\title{
OVERVIEW OF US ACADEMIC PROGRAMS IN ELECTRIC PROPULSION
}

\author{
Rodney L. Burton \\ University Of Illinois At Urbana-Champaign \\ Contributing Authors: \\ Michael M. Micci Pennsylvania State University \\ Iain D. Boyd Cornell University \\ Manual M. Martinez-Sanchez Massachusetts Institute of Technology \\ Dennis R. Keefer University of Tennessee Space Institute \\ Nikos A. Gatsonis Worcester Polytechnic Institute \\ Mark A. Cappelli Stanford University \\ Alec D. Gallimore University of Michigan \\ Peter J. Turchi Ohio State University \\ Paul J. Wilbur Colorado State University \\ Ivana Hrbud Auburn University \\ Edgar Y. Choueiri Princeton University \\ Rodney L. Burton University Of Illinois At Urbana-Champaign
}

Graduate-level research in electric propulsion has been a staple of aerospace engineering and mechanical engineering advanced degree programs for about 40 years. These programs have brought to the field an important fundamental research component to balance contributions from government and industry laboratories. The research has historically covered just about every type of electric thruster ever considered, but over the last few years has begun to focus only on efficient, low mass electric propulsion systems with a strong potential for spaceflight applications.

Historically, research activities in electric propulsion are typically recorded as AIAA preprints and as articles in the AIAA Journal of Propulsion and Power. A significant number of articles are also published in the AIAA Journal of Thermophysics and Heat Transfer, the Journal of Spacecraft and Rockets, the AIAA Journal, and the journals of the IEEE. Additional important sources are the papers published in the proceedings of the biannual International Electric Propulsion Conference. These proceedings are available from the Electric Rocket Propulsion Society in the form of either hardcopy or CD-ROM.

Many graduates of electric propulsion programs have remained in the field. The authors listed above include several current research investigators who earned their degrees in the 1960's and early 1970's. Many of today's graduates are also remaining in the electric propulsion research arena in industry, government, and academia.

\section{Acknowledgments}

The idea for an overview paper covering academic research in electric propulsion came from E. Choueiri, for which he is to be commended. Thanks also to the contributing authors listed above who were remarkably punctual with their contributions. The job of corralling the authors and organizing their disparate contributions fell to my students S. Keener and T. Smart, and I thank them. 


\title{
LOW POWER MICROWAVE ARCJET CHARACTERIZATION AND DEVELOPMENT
}

\author{
Michael M. Micci \\ Department of Aerospace Engineering \\ The Pennsylvania State University
}

Microwave arcjets use microwave energy to heat a gas to plasma temperatures within a resonant cavity followed by an expansion through a converging-diverging nozzle to obtain thrust. The goals of this research are to characterize and enhance the performance of low power ( 100 Watts) microwave arcjets for use in stationkeeping, attitude control and orbit raising and changing for mini and microsatellites. Microwave power at both 2.45 and 7.5 $\mathrm{GHz}$ is being investigated. Thruster performance in terms of specific impulse and efficiency and overall system efficiency as a function of microwave frequency are being compared. Since the major loss mechanisms in low power microwave arcjets will occur in the low Reynolds number nozzle expansion, optical diagnostics are being applied to the nozzle flow to quantify these losses. These measurements will be combined with Direct Simulation Monte Carlo (DSMC) numerical models to develop a methodology for improved small nozzle design.

The research is currently funded by the Air Force Office of Scientific Research, with additional support by the Air Force Research Laboratory at Edwards AFB. 


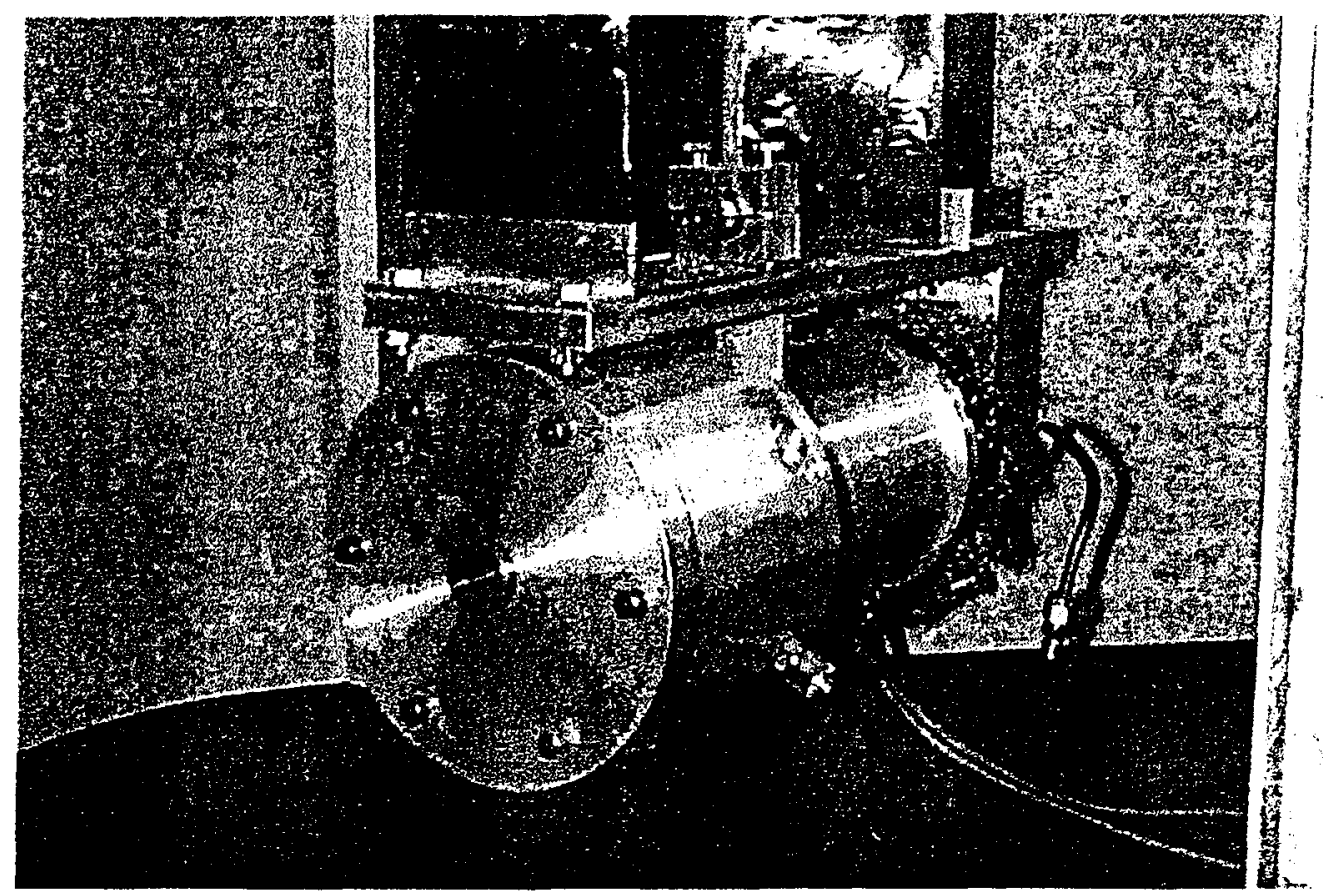

$2.45 \mathrm{GHz}$ Microwave Arcjet on Thrust Stand.

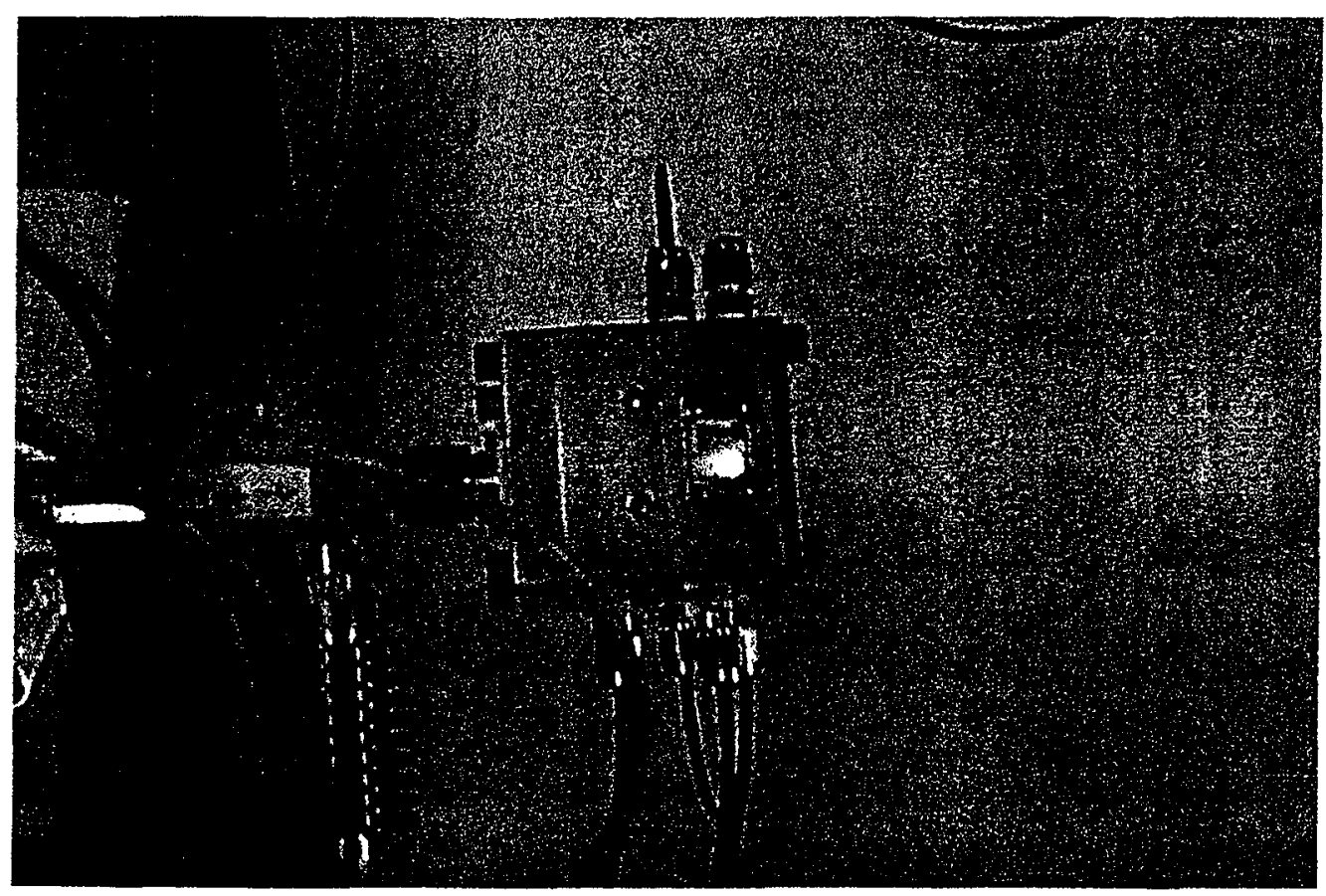

7.5 GHz Microwave Arcjet Operating at 100 Watts on Helium Propellant. 


\title{
COMPUTATIONAL PREDICTION OF PLUME FLOWS IN ELECTRIC THRUSTERS
}

\author{
Iain D. Boyd \\ Cornell University
}

Ammonia Arcjet

We have developed a code using the direct simulation Monte Carlo method (DSMC) for computing the nozzle and plume flows from resistojets and arcjets. The goals of the work are to improve device design and to predict spacecraft interaction effects. Detailed thermo-chemical kinetics models are implemented including rotational and vibrational relaxation, dissociation and ionization reactions. A simple plasma model for ohmic heating is also implemented. Previous studies have considered nitrogen and hydrogen flows. In our latest work, the code has been applied to predict back flow contamination from the ammonia arcjet to be flown on the USAF ESEX flight experiment. The result shown is for the thruster in cold-flow mode. This simulation involved a very large Monte Carlo computation employing 11 million particles on 32 processors of an IBM SP-2. Ultimate assessment of the accuracy of the model will be made through direct comparison with flight measurements of ammonia flux obtained using quartz-crystal-microbalances (QCM's).

The work is funded by AFOSR.

TAL D55 Hall Thruster Plume

We have developed a Particle-In-Cell (PIC)-DSMC code for computing plume flows from Hall thrusters. The primary goal is prediction of spacecraft interaction effects. PIC simulates the plasma-dynamics of the ions directly and uses the Boltzmann relation for the electrons; DSMC simulates all collision behavior including charge exchange. We have applied our code to the SPT-100 and the D55 TAL (example results shown here). We conclude that our code is good for flow near the axis, but inaccurate at large angles off-axis and in the back flow regime. A much more detailed (and numerically expensive) treatment of the electrons will be required to accurately model these regions.

The work is funded by NASA Lewis Research Center. 


\section{DSMC Computation of Plume Back Flow For an Ammonia Arcjet}

Iain D. Boyd and Keith C. Kannenberg, Cornell University, Ithaca, NY 14853

Funding provided by AFOSR Space Propulsion \& Power Program (F49620-96-1-0091)
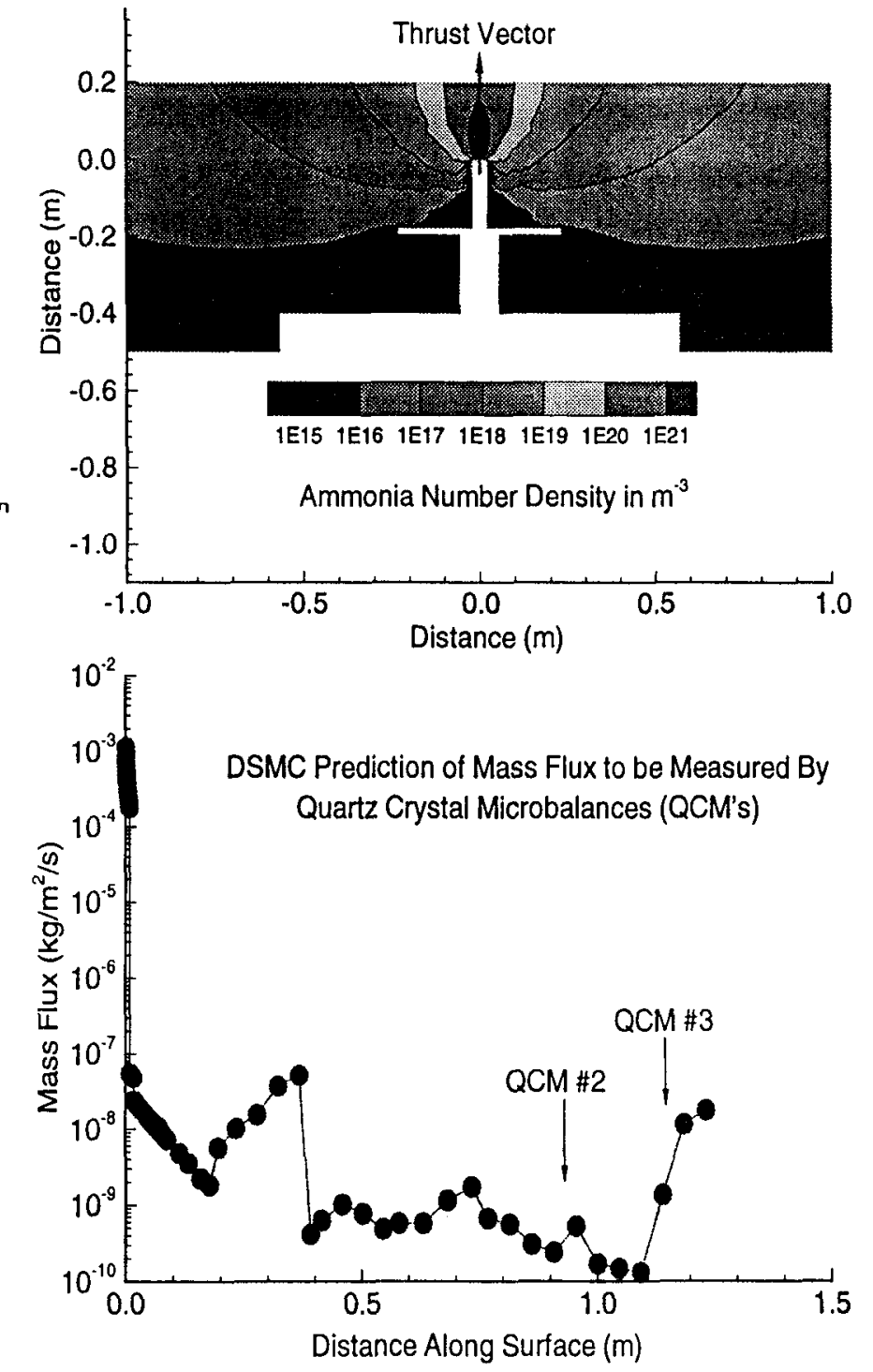

\section{Goal:}

Develop a computer code to model nozzle and plume flows of arcjets for device design and prediction of spacecraft interaction effects.

\section{Models/Algorithms:}

Chemical kinetics + simple plasma model.

Direct Simulation Monte Carlo (DSMC) method:

- implemented on parallel computer (IBM SP2)

- 11 million particles, 32 processors employed.

\section{Example shown here:}

Prediction of ammonia contamination in back flow region to be measured by ESEX flight experiment.

\section{Relevant publications:}

Boyd ID, Physics of Fluids, Vol. 9, 1997, p. 3086.

Boyd ID, J Propulsion \& Power, Vol. 13, 1997, p. 775.

Kannenberg KC \& Boyd ID, AIAA-98-2755, June 1998.

Boyd ID et al., AIAA-98-3552, July 1998.

\section{Contact:}

Iain D. Boyd, (607) 255-4563, boyd@mae.cornell.edu Web: http://fluids.mae.cornell.edu/Boydgroup 


\section{PIC-DSMC Computation of SPT and TAL Hall Thruster Plumes}

Iain D. Boyd and Douglas B. VanGilder, Cornell University, Ithaca, NY 14853

Funding provided by NASA Lewis Research Center (Grant NAG3-1451)

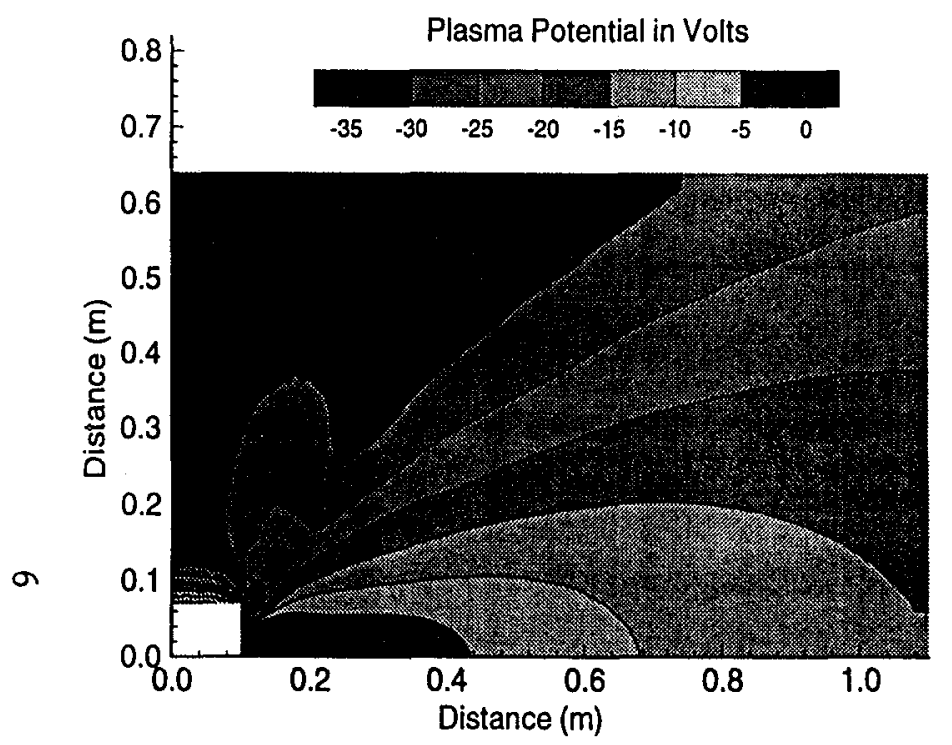

\section{Goal:}

Develop a computer code to model plume flows of SPT and TAL Hall thrusters for prediction of spacecraft interaction effects.

\section{Models/Algorithms:}

Particle-In-Cell (PIC) plasma model.

Direct Simulation Monte Carlo (DSMC) method:

- charge exchange collisions.

Code implemented on parallel computer (IBM SP2)

\section{Example shown here:}

Plasma potential contours of D55-TAL Hall thruster and

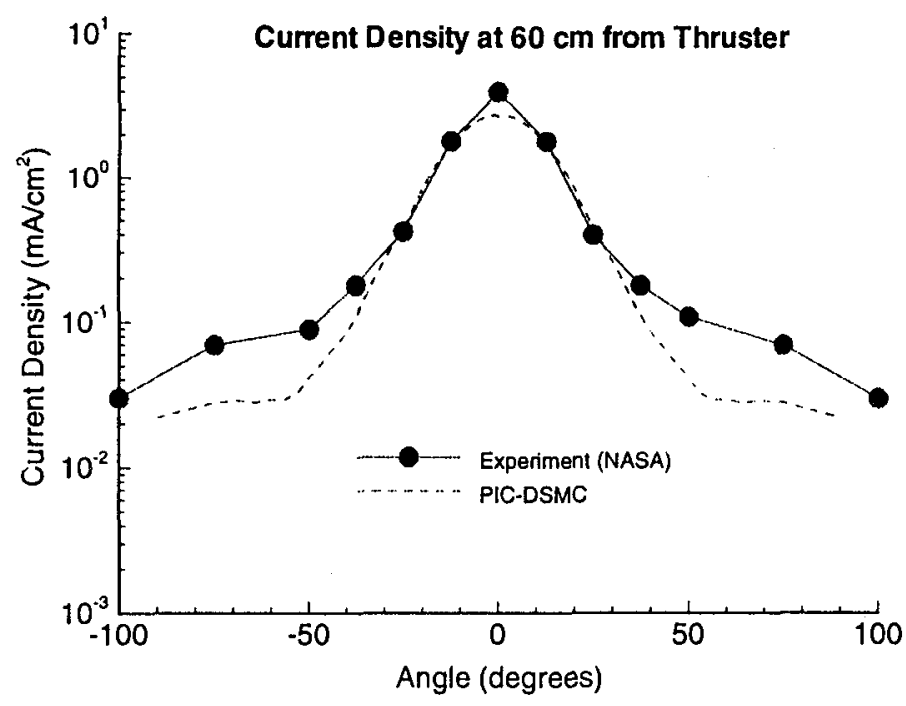

\section{Relevant publications:}

Boyd ID, et al., IEPC-97-20, September 1997.

VanGilder DB et al., IEPC-97-182, September 1997.

VanGilder DB \& Boyd ID, AIAA-98-3797, July 1998.

Boyd ID, AIAA-98-3798, July 1998.

\section{Contact:}

Iain D. Boyd, (607) 255-4563, boyd@mae.cornell.edu Web: http://fluids.mae.cornell.edu/Boydgroup 


\title{
FUNDAMENTAL RESEARCH ON ELECTRIC MICROTHRUSTERS
}

\author{
Manuel M. Martinez-Sanchez \\ Massachusetts Institute of Technology
}

\section{MICROTHRUSTERS:}

This work determines minimum performance levels for various micro-EP technologies to perform several selected microsatellite cluster missions. It considers in some detail the linear ion engine concept proposed by JPL, which is analyzed using Brophy's model and Arakawa's ancillary codes. The first conclusion was that the highest conceivable B field would yield negligible electron confinement benefits at the $0.1 \mathrm{~mm}$ scale, and could be ignored. Without it, and given the very open-faced geometry, the beam ion production costs were in excess of $4000 \mathrm{~V}$. As a consequence, the micro-ion engine, in the configuration studied, was found to be inferior for the missions considered to cold gas propulsion. Improvements are required in both electron and neutral gas confinement; with an assumed "grid" transparency to neutrals of 0.26 , the ion cost dropped to $1100 \mathrm{~V}$.

This research was done by G. Yashko, under contract to JPL ("Ion Micropropulsion and Cost Modeling for Satellite Clusters," MS Thesis, MIT, Aero/Astro, June 1998).

\section{ARCJETS}

The Hydrogen arcjet model of S. Miller was extended to include the presence of small amounts of cesium. The objective was to critically evaluate the 1-D results of F. Oyerokun (IEPC 95-236) and his subsequent stability analysis (IEPC 97-012), which had found that levels of seeding of the order of $1-2 \%$ by mass could virtually eliminate arcjet frozen losses, while retaining specific impulses of the order of $800 \mathrm{~s}$. A critical consideration was the ability of the seeded discharge to remain diffuse without snapping into the familiar constricted configuration with high ionization of the parent gas. The work has confirmed this (as shown in the figure), and has added realism in many areas of the problem, while confirming in its main outlines the previous results. Because of the near-uniform current distribution, the constrictor will have to be insulating or segmented, but this may be possible, since the gas temperature does not exceed about $3000 \mathrm{~K}$.

This work was done by D. K. Robertson: "A Two-Dimensional, Non-Equilibrium Numerical Model of an Alkali-Seeded Hydrogen Arcjet Thruster," MS Thesis, MIT Aero/Astro, June 1998. It will be presented at the 34th JPC.

\section{HALL THRUSTERS (COMPUTATIONAL)}

There are several efforts underway in this area, including that by M. Fife, J. Szabo and S. Qarnain, all of whom will be presenting papers at the 34th JPC. The relevant figure is from S. Qarnain ("Issues Regarding a Complete Computational Model of a Hall Thruster, from the Acceleration Channel Through the Plume", MS Thesis, MIT, Aero/Astro, June 1998). This is an extension of previous 2-D and 3-D Hall plume modeling work by D. Oh (MIT Ph.D. Thesis, Feb. 1997). The current computational plume model tracks the formation of chargeexchange ions in the near plume, and their subsequent self-consistent trajectories outside the plume. When these trajectories impinge on external surfaces, such as solar panels, the code uses angle and energy-dependent sputtering models to accumulate surface loss at various locations. Qarnain has also upgraded the earlier code by using as initial conditions the thruster exit plane results of 2-D PIC computations using the code developed by M. Fife and J. Szabo (IEPC 95-240, AIAA 97-3052), after verifying the basic accuracy of these results against available exit-plane data.

This work is funded by Phillips Lab, Busek Co and the AFOSR.

\section{HALL THRUSTERS (EXPERIMENTAL)}


The figures refer to a detailed near-plume probe survey of an SPT-70 thruster done by M. Fife recently at the Phillips Lab. A paper will be presented at the 34th JPC. The particular map shown gives the plasma density in a meridional plane, covering the first $4 \mathrm{~cm}$. A noteworthy feature is the conical high-density region emanating from the thruster's exit plane center, which is very conspicuous visually as well. This feature is also reproduced by the results of PIC simulations, and is the result of many ion trajectories crossing on or near the symmetry axis. One other significant, but not well understood feature is an external electron temperature peak, about $1.5 \mathrm{~cm}$ in front of the exit plane. Work is underway to harmonize these data with Fife's own computational model. Other experimental work in progress involves V. Khayms' 50 watt Hall thruster (AIAA 96-3291), which was recently performance-tested at the AF Phillips Lab. We are temporarily withholding publication of the results, pending repetition to reduce some uncertainties in the measurements of the very low flow rates involved. The current results indicate peak efficiency of $27 \%$ at a specific impulse of $2070 \mathrm{~s}$. 


\section{Electric Propulsion Program at MIT}

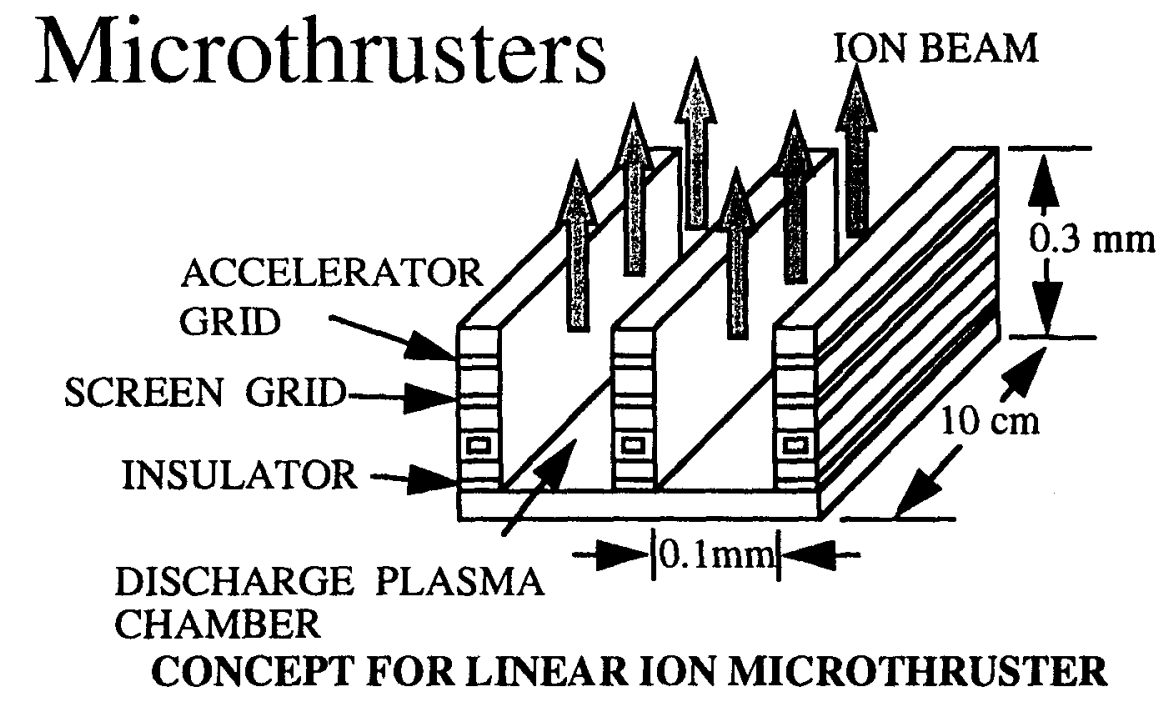

Microthruster technology has been evaluated for satellite cluster formation flying.

Goals:

- Evaluate performance through modeling

- Determine feasibility of using ion microthrusters for cluster applications

Sponsors: JPL, AFOSR

\section{Arcjets}

Arcjets operate with frozen losses of $50 \%$. To reduce frozen loss, a small amount of an easily ionizable substance can be added.

Goals:

- Model a cesium-seeded hydrogen arcjet to validate theory

- Characterize cesium-seeded arcjet performance

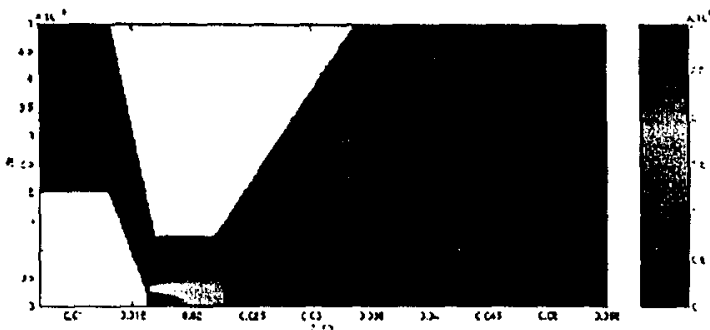

Figures:

Top: Current density in conventional hydrogen arcjet.

Bottom: Current density in cesium-seeded arcjet.

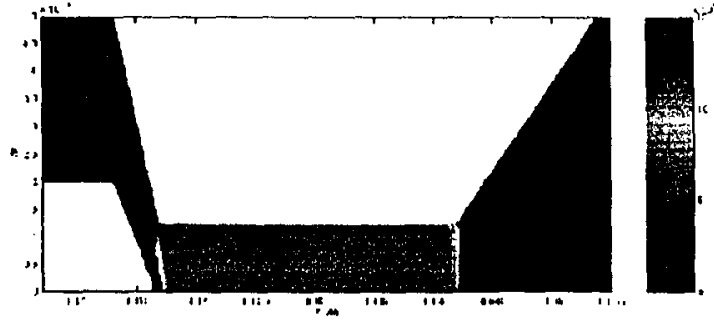




\section{Electric Propulsion Program at MIT}

\section{Hall Thrusters}

Computational Program

Hall thruster technology is at the forefront of EP research.

Our goals are to:

- Characterize the acceleration channel and plume physics of the Hall thruster

- Develop an end-to-end, desktop computational model for design

Figure:

Hall thruster mounted on satellite bus at a $45^{\circ}$ cant angle. Potential contours shown.

Sponsor: AFOSR

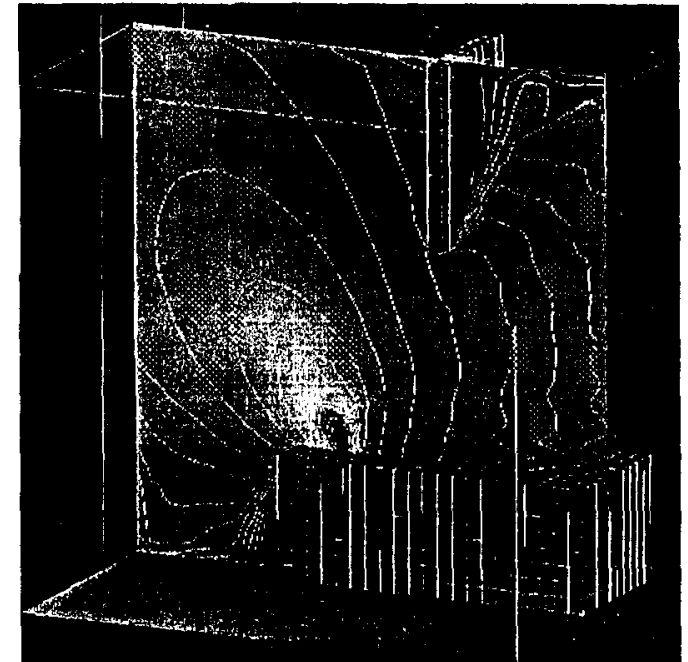

Figures:

Top Right:

Experimental set-up

for testing an SPT-

70.

Near Right: Triple probe measurements of electron density in the SPT-70

plume. $(\mathrm{Vd}=300 \mathrm{~V}$, $\dot{\mathrm{m}}=2.34 \mathrm{mg} / \mathrm{s}$ )

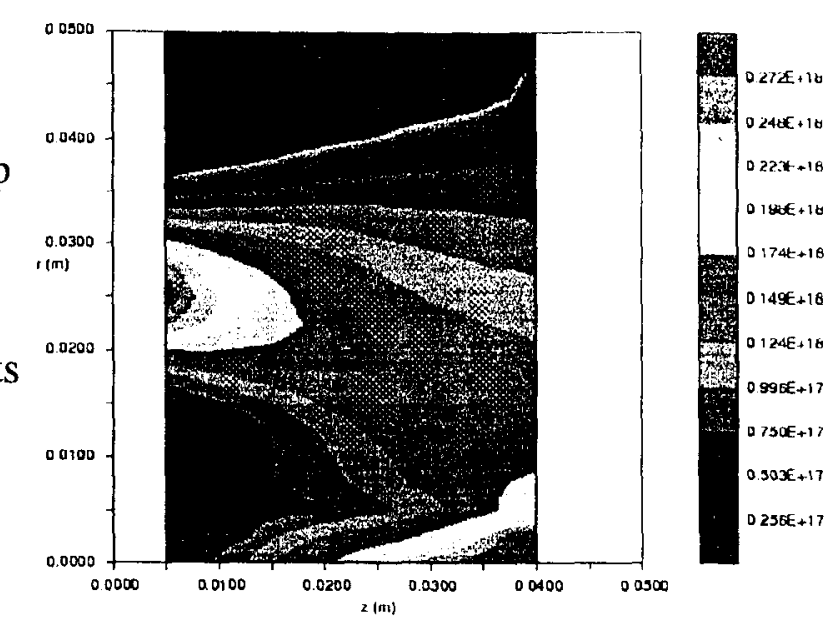




\title{
ELECTRIC PROPULSION ACTIVITIES AT THE UNIVERSITY OF TENNESSEE SPACE INSTITUTE
}

\author{
Dennis R. Keefer \\ The University of Tennessee Space Institute
}

Current electric propulsion activities at the University of Tennessee Space Institute (UTSI) focus on: (1.) validating plasma chemical kinetic models for use in electric thruster codes, and (2.) investigating coaxial pulsed plasma thrusters (PPT's).

Validation of the plasma chemical kinetics models is accomplished by comparing measured conditions of nonequilibrium plasmas generated in the UTSI cascade arc facility with computer simulations of these nonequilibrium plasmas. The cascade arc was utilized to produce $50 \mathrm{~A}$ hydrogen arcs at absolute pressures of 2.0 and 6.0 psi. Spatially resolved spectral emission data were collected using a two dimensional Optical Multichannel Analyzer (OMA). Radial distributions of electron number density were determined by fitting theoretical line profiles to the experimentally measured Abel inverted emission line profiles. The measured electron densities were compared to values predicted by nonequilibrium cascade arc simulations using the UTSI Cascade Arc Plasma Simulation (CAPS) code. The experimental electric field has been accurately predicted by varying chemical kinetics in the CAPS code. Kinetic models used at the University of Illinois gave the best agreement with the cascade arc measurements for hydrogen at both pressures. Comparisons of the radial distributions of electron density for the 50 A hydrogen arc at $6 \mathrm{psi}$ are shown on the figure. Similar results were obtained for the 50 A hydrogen arc at 2 psi. Electron number density profiles for simulated ammonia and hydrazine were also obtained for arcs at pressures of 2.0, 6.0 , and $10.0 \mathrm{psi}$. These hydrogen/nitrogen mixture data can be used in comparisons with a hydrogen/nitrogen version of the CAPS code to be developed in the future. This work was supported by the Air Force Office of Scientific Research under contract \#F49620-97-1-0223.

Two coaxial PPT's were designed at UTSI and tested at several initial stored energies. The overall thruster design utilizes the discharge within a conical cavity consisting of a copper cathode, a plastic propellant and a tungsten anode to produce a pulse of plasma. One nozzle has an exit diameter of 0.5 in., while larger nozzle is 0.75 in. at the exit; both thrusters have a $60^{\circ}$ cone angle. A capacitive discharge circuit was designed and fabricated to power the PPT's. Two different propellants were used for the experiments, Teflon $\left(\mathrm{CF}_{2}\right)_{n}$ and polyethylene $\left(\mathrm{CH}_{2}\right)_{n}$. The polyethylene was expected to give a higher specific impulse because of its lower average molecular weight. The exhaust velocity was measured using a two beam laser interferometer. In order to verify the correctness of the results with the interferometer, a high speed camera was used to obtain images of the exhaust plume from which the velocity could also be measured. The mass ablation was also measured to give an insight in the ablation behavior of the thruster over a broad initial stored energy range. Along with the values mentioned above, the voltage and current input into the thruster were also measured. Spectral measurements of the exhaust plume were also recorded. For the smaller nozzle, the measured exhaust velocity reached a maximum of $14.6 \mathrm{~km} / \mathrm{s}$ using Teflon and $21.7 \mathrm{~km} / \mathrm{s}$ using polyethylene. For the larger nozzle, the Teflon values were about the same $(14.4 \mathrm{~km} / \mathrm{s})$, however, the exhaust velocity using polyethylene increased to $29.8 \mathrm{~km} / \mathrm{s}$. These results led to a conclusion that thermal processes dominate the acceleration of the plasma. Thrust efficiencies up to $10 \%$ for polyethylene and $5 \%$ for Teflon were measured for the large nozzle. MACH2 simulations of these PPT's are currently being run at UTSI. Using a preliminary radiation model, $\mathrm{MACH} 2$ overpredicts the exhaust velocity by about $57 \%$. However, the simulations do capture important characteristics of the exiting plasma plume.

Graduate Students:

Trevor Moeller -- cascade arc experiment.

Dan Thomas - PPT MACH2 simulations

Thomas Walloscheck -- PPT experiment 


\section{UTSI Cascade Arc Experiment}

- Arc experiment to validate plasma

50 A Hydrogen Arc at 6 psi

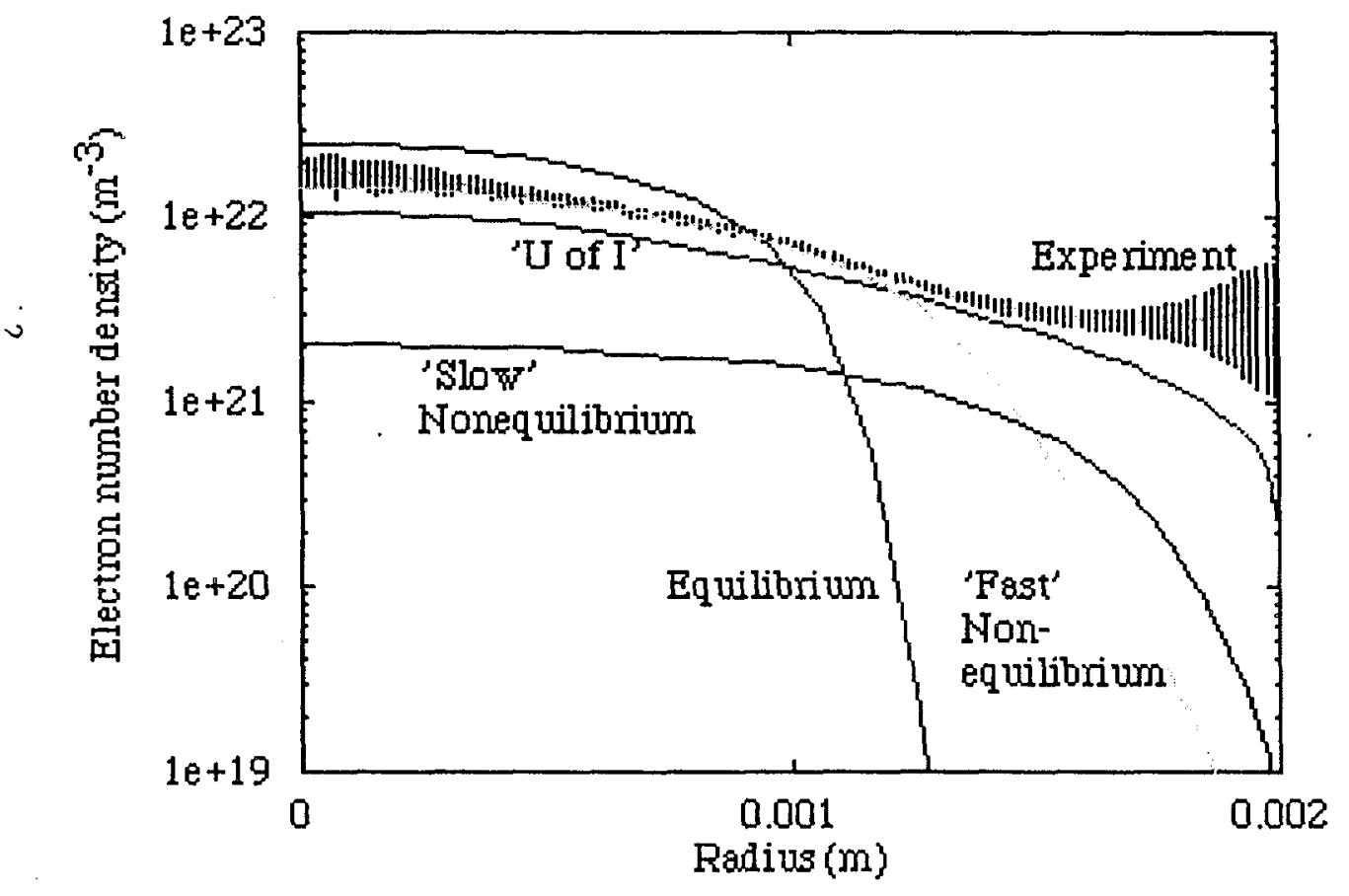
kinetic models for use in electric thruster codes.

- Chemical kinetics used at the University of Illinois result in arc simulations that closely match experimental data.

- Dennis Keefer, PI

- Trevor Moeller, Research Assistant

- Supported by AFOSR. 


\section{UTSI Conical PPT Experiment}
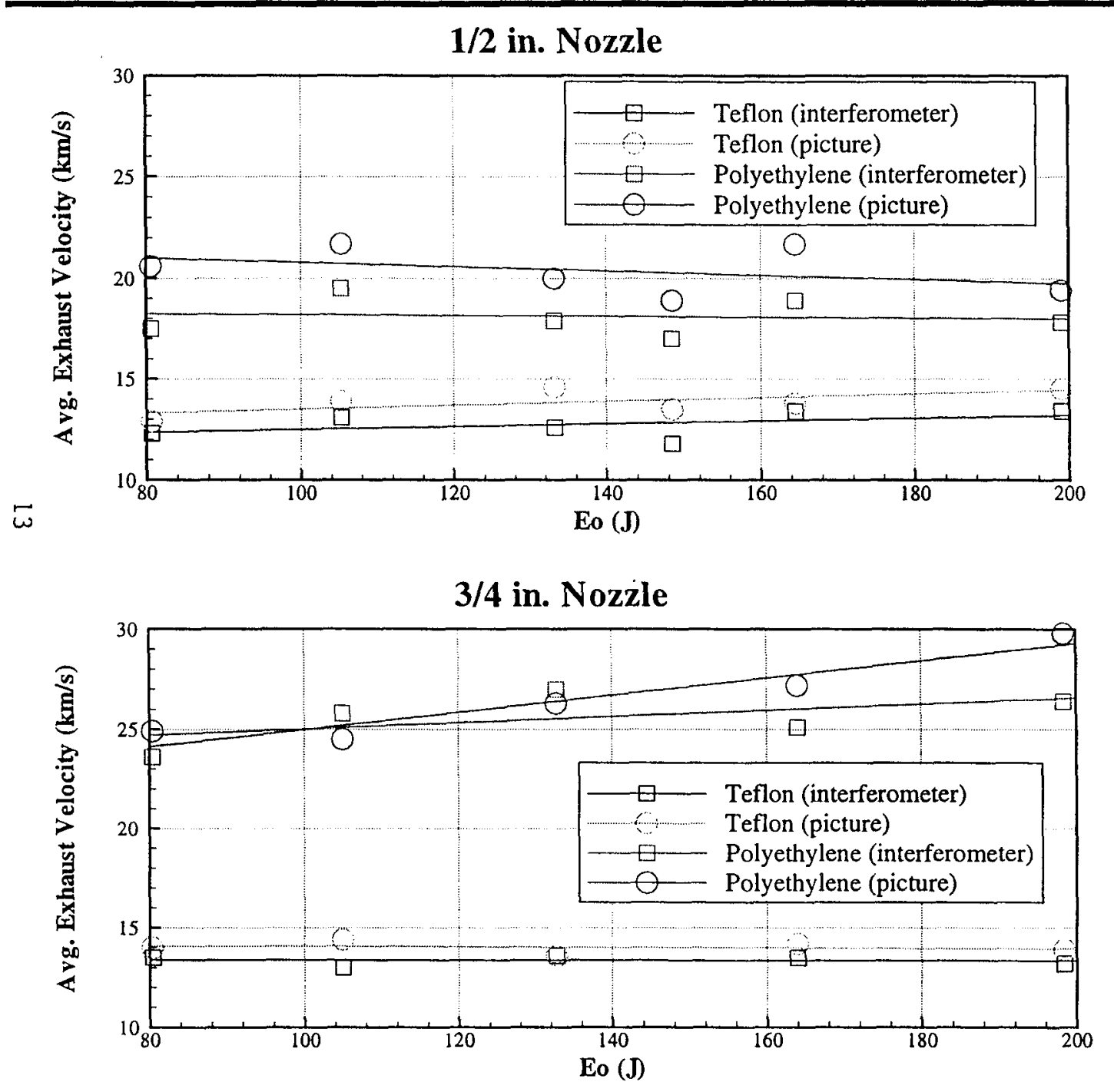

- Experiment to investigate coaxial PPT's.

- Velocities measured with laser velocimeter and high speed photography

- Simulations of experiment using Mach2 have begun.

- Dennis Keefer, PI

- Dan Thomas and Thomas Walloscheck, Graduate Research Assistants

- Funded by AFOSR and UTSI Center for Laser Applications

University of Tennessee Space Institute

Center for Laser Applications 


\title{
THE ELECTRIC PROPULSION PROGRAM AT THE COMPUTATIONAL GAS \& PLASMADYNAMICS LAB (CGPL)
}

\author{
Nikos A. Gatsonis \\ Worcester Polytechnic Institute
}

The activities of the Electric Propulsion Program at WPI's CGPL aim at developing an advanced predictive ability for EP induced environments, assessing potential induced environment/spacecraft interactions and assisting in EP spacecraft integration. To accomplish its goals the Program consists of three complementary efforts:

1. Advanced Computational Modeling of EP Plumes CGPL is developing for NASA LeRC a PPT plume model based on a hybrid methodology that combines the Direct Simulation Monte Carlo (DSMC), Particle-in-Cell (PIC) and fluid computational techniques. ${ }^{1-4}$ Future work will extend the code into 3-d to include realistic spacecraft geometries. Earlier collaborative work with MIT resulted in a PIC/Fluid model for ion thruster plumes. 5,6

2. Experimental Investigation of EP Induced Environments CGPL in collaboration with NASA staff developed proper diagnostics and performed several plume experimental investigations using various PPT models at the LeRC EP facilities. ${ }^{6-14} \mathrm{~A}$ similar investigation for Gas-Fed PPTs is underway in collaboration with JPL. ${ }^{15,16}$ In addition, in a recent effort with JPL the erosion of the NSTAR ion thruster grid was investigated. ${ }^{17}$

3. Analysis of EP/Spacecraft Integration Issues for EP Missions Emphasis is placed on CGPL's participation in the design of missions where EP/Spacecraft Integration issues are important. Recent work on the DS-3 mission in collaboration with JPL resulted in the development of a trajectory and contamination analysis model. ${ }^{18}$ This effort is continuing with the analysis of PPT plume/communication interactions for the revised DS-3 mission. ${ }^{19}$

The WPI/CGPL EP Program involves graduate students, as well as undergraduates completing their Major Qualifying Project (a senior thesis degree requirement at WPI equivalent to three courses). Therefore, the Program has strong educational and research components. Support for the Program has been provided by NASA LeRC and JPL, Mass Space Grant Consortium and WPI.

Relevant Publications and Work in Progress:

1. Gatsonis, N. A. and X. Yin, "Hybrid (Fluid/PIC/DSMC) Simulation of Partially Ionized Jets," 21st International Symposium on Rarefied Gas Dynamics, France, July 1998.

2. Gatsonis, N. A and Yin, X., "Theoretical and Computational Analysis of Pulsed Plasma Thruster Plumes," IEPC-97-041, 25th International Electric Propulsion conference, Cleveland OH, Aug. 1997.

3. Yin, X. and Gatsonis, N. A, "Numerical Investigation of Pulsed Plasma Thruster Plumes," IEPC-97-036, 25th International Electric Propulsion Conference, Cleveland OH, Aug. 1997.

4. Yin, X. , "An Axisymmetric Hybrid Model of PPT Plumes", Ph.D. Dissertation under preparation, WPI.

5. Samantha Roy, R., Hastings, D. E. and Gatsonis, N. A., "Ion-Thruster Plume Modeling for Backflow Contamination," Journal of Spacecraft and Rockets, V33, 4, 1996.

6. Samantha Roy, R., Hastings, D. E. and Gatsonis, N. A., "Numerical Study of Spacecraft Contamination and Interactions by Ion-Thruster Effluents," Journal of Spacecraft and Rockets, V33, 4, 1996.

7. Eckman, R., Gatsonis, N. A, Cameron, E., Byrne, L., Pencil, E., "Triple Langmuir Probe Measurements in the Plume of a Pulsed Plasma Thruster," ASME/AIAA 34th Joint Propulsion Conference, AIAA--98-3806, Cleveland OH, July 1998.

8. Eckman, R. " Experimental Investigation and Modeling of PPT Plumes", MS Thesis under preparation, WPI.

9. Byrne, L., Cameron, E., " Triple Probe Measurements in PPT Plumes", MQP Report, NAG- 9801, WPI, $7 / 1998$.

10. Eckman, R., Gatsonis, N. A, Myers, R., Pencil, E., "Experimental Investigation of the LES 8/9 Pulsed Plasma Thruster Plume," IEPC-97-026, 25th International Electric Propulsion conference, Cleveland OH, Aug. 1997. 
11. Myers, R., Arrington, L. A., E. Pencil, J. Carter, J. Heminger, N. Gatsonis, "Pulsed Plasma Thruster Contamination", AIAA 96-2729, ASME/AIAA 32nd Joint Propulsion Conference, July 1996.

12. D. Papini, T. Slade, "Pulsed Plasma Thruster Plume Investigation," MQP Report, NAG- 9701, WPI, 4/1997

13. Eckman, R., Santesson, M., "Pulsed Plasma Thruster Diagnostics," MQP Report NAG- 9601, WPI,11/ 1996.

14. Carter, J., Heminger, J., "Pulsed Plasma Thruster Plume Characterization," MQP Report NAG-9503, WPI, $11 / 1995$.

15. Chauhan, R., McInhenny, J., "Gas-Fed PPT Plume Investigation", MQP

16. M. Gagne, "Gas-Fed PPT Plume Investigation and Modeling," MS Thesis under preparation, WPI.

17. Baker, K., Kodys, A., "Grid Erosion Analysis of the NSTAR Ion Thruster," MQP Report NAG-9704, WPI, 2/1998.

18. Gagne, M., Gold, S., "DS-3 Trajectory and Contamination Analysis," MQP Report NAG- 9703, WPI, 4/1998.

19. Gold, S. "Analysis of PPT Plume/Communications Interactions for the DS-3 Mission", MS

Thesis under preparation, WPI. 


\section{Prof. Nikos A. Gatsonis \\ Computational Gas \& Plasmadynamics Lab \\ Mechanical Engineering Dept. \\ WPI}

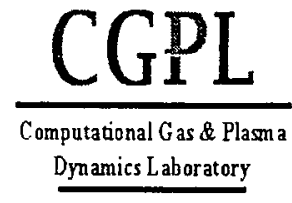

SAMPLE OF RESULTS

-Hybrid (Particle-Fluid) Model of the LES 8/9 PPT Plume

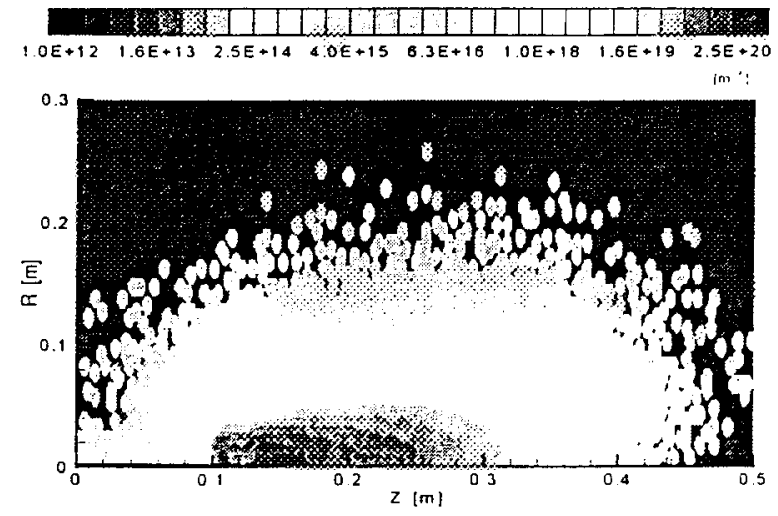

Ion Density $t=6 \mu \mathrm{sec}$

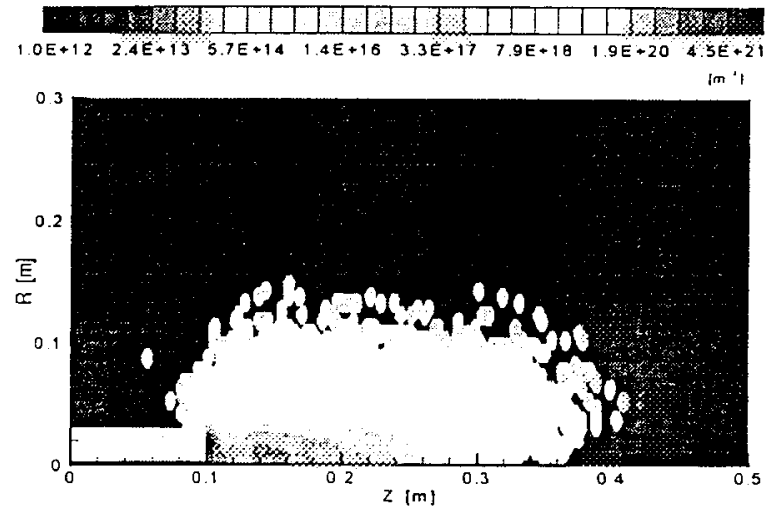

Neutral Density $\mathrm{t}=6 \mu \mathrm{sec}$

\section{- Experimental Investigation of the LES 8/9 Plume}

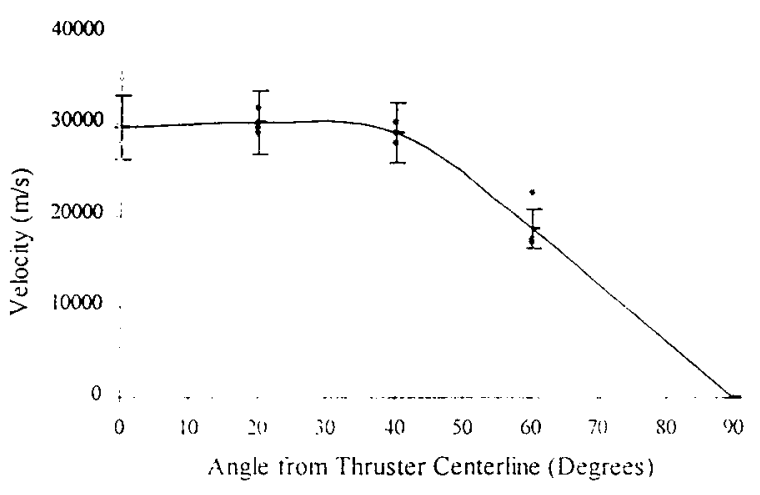

Ion Velocity Profiles

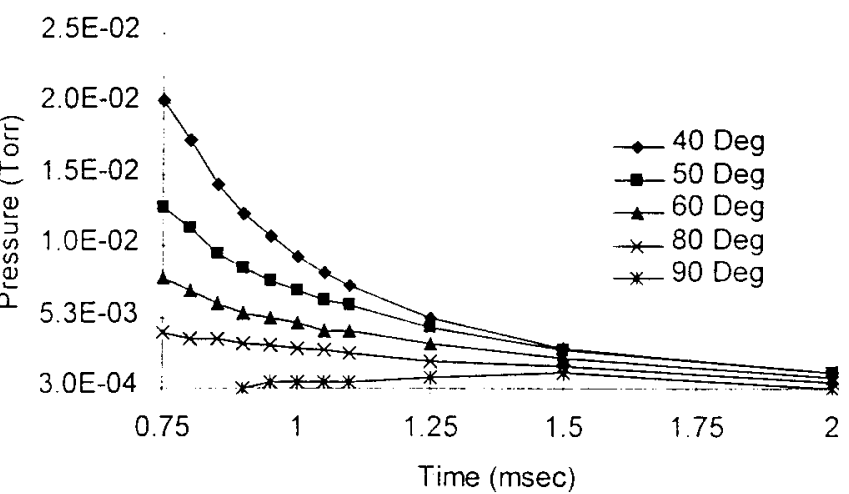

Neutral Pressure

\section{RECENT PUBLICATIONS}

1. Gatsonis. N. A. and X. Yin, "Hybrid (Fluid/PIC/DSMK) Simulation of Partially lonized Jets," 21 st International Symposium on Rarefied Gas Dynamics, France, July 1998.

2. Eckman, R., Gatsonis, N.A., Cameron, E., Byrne, L.. Pencil, E., "Triple Langmuir Probe Measurements in the Plume of a Pulsed Plasma Thruster," 34th Joint Propulsion Conference, Cleveland OH, July 1998.

3. Gatsonis, N.A. and Yin, X., "Theoretical and Computational Analysis of Pulsed Plasma Thruster P/unes," IEPC97-041, 25th International Electric Propulsion conference, Cleveland OH, Aug. 1997.

4. Yin, X. and Gatsonis, N.A., "Numerical Investigation of Pulsed Plasma Thruster Plumes," IEPC-97-036, 25th International Electric Propulsion Conference, Cleveland OH, Aug 1997.

5. Eckman, R., Gatsonis, N.A., Myers, R., Pencil, E., "Experimental Investigation of the LES 8/9 Pulsed Plasma Thruster Plume." IEPC-97-026, 25th International Electric Propulsion conference, Cleveland OH, Aug. 1997.

6. Baker, K.. Kodys, A., "Grid Erosion Analysis of the NSTAR Ion Thruster," MQP Report NAG-9704, WPI, $2 / 1998$.

7. Gagne, M. Gold. S., "DS-3 Trajectory and Contamination Analysis," MQP Report NAG-9703. WPI. 4/1998. 


\section{TRANSIENT STUDIES OF CLOSED-DRIFT HALL DISCHARGES $\ddagger$}

Prof. Mark A. Cappelli, Principal Investigator, William A. Hargus and Nathan B. Meezan, Graduate Assistants Stanford University

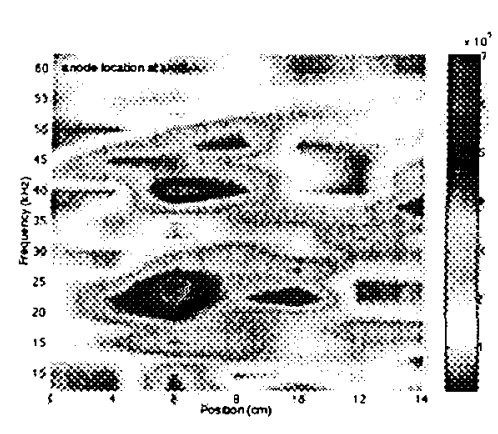

(a) low specific energy $(65 \mathrm{~V}, 3.35 \mathrm{~A}, 3 \mathrm{mg} / \mathrm{s})$

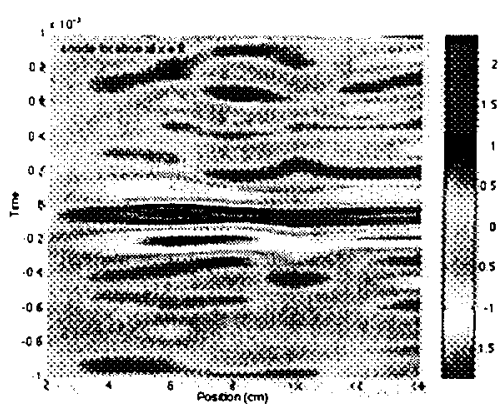

(d) low specific energy $(65 \mathrm{~V}, 3.35 \mathrm{~A}, 3 \mathrm{mg} / \mathrm{s})$

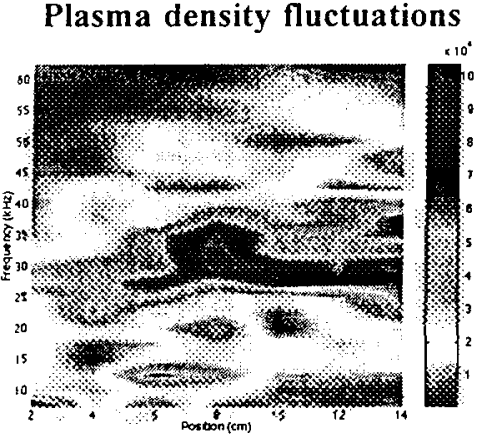

(b) moderate specific energy $(75 \mathrm{~V}, 3.7 \mathrm{~A}, 3 \mathrm{mg} / \mathrm{s})$

\section{Cross-correlation plots}

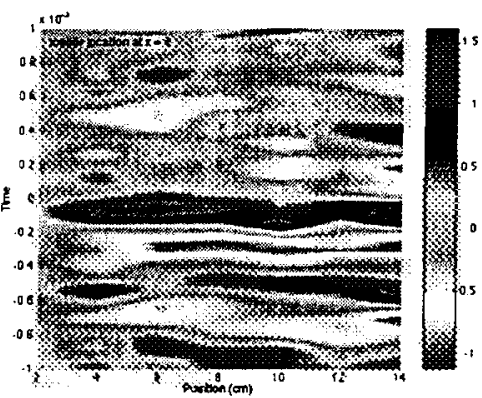

(e) moderate specific energy $(75 \mathrm{~V}, 3.7 \mathrm{~A}, 3 \mathrm{mg} / \mathrm{s})$

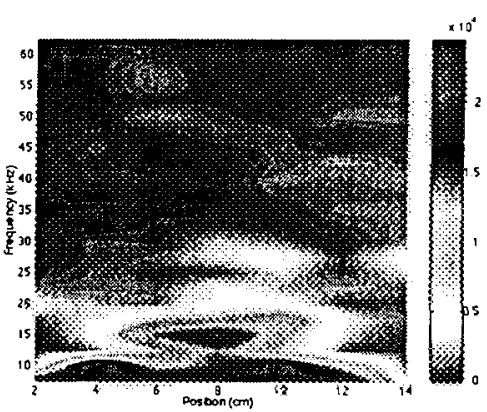

(c) high specific energy $(100 \mathrm{~V}, 2.3 \mathrm{~A}, 2 \mathrm{mg} / \mathrm{s})$

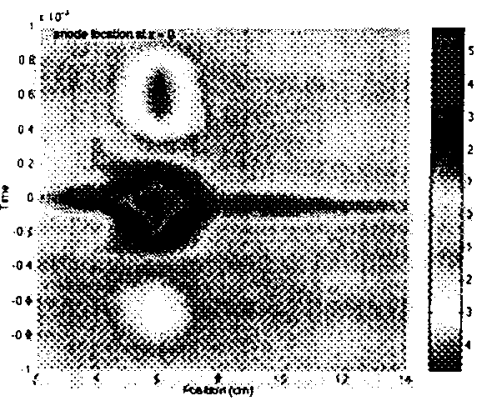

(f) high specific energy

$(100 \mathrm{~V}, 2.3 \mathrm{~A}, 2 \mathrm{mg} / \mathrm{s})$

Closed drift Hall accelerators are known to exhibit a rich spectrum of transitory phenomenon which are believed to be critical to their operation. Using a variety of electrostatic probes, the structure (spatial and temporal) of these discharges has been probed within the ionization and acceleration zone (within the discharge channel). In the above figure, we illustrate some of the interesting transitory phenomenon and their variations with changes in operating conditions, captured using two low-impedance negatively-biased probes for ion collection (to map plasma density), separated azimuthally by $45^{\circ}$. The variation in the spectral plasma density fluctuations with position along the channel (the anode is at $\mathrm{x}=0$ ) for relatively low, moderate, and high specific energy operation are shown in the above Figures a) through c). It is apparent that there is a significant variation in the spectral density fluctuations with both position and operating conditions. At low specific energy (corresponding to operation along the ionization branch of the current-voltage characteristic of the discharge), strong disturbances at frequencies of approximately $25 \mathrm{kHz}$ (and higher harmonics) are seen near anode. At relatively high specific energies (corresponding to operation along the current saturation branch of the current-voltage characteristic), these $25-30 \mathrm{kHz}$ waves are overtaken by lower frequency $(\sim 10 \mathrm{kHz})$, stronger disturbances that are widespread and throughout the channel. An examination of the cross-correlation of the two probe traces, see Figures (d) through (f) indicate that the low frequency disturbances at high specific energies are strongly correlated, representing homogeneous fluctuations in plasma density. The disturbances at lower specific energies are also highly correlated, and represent azimuthal traveling waves, with velocities near the $\mathbf{E} \times \mathbf{B}$ electron drift velocities, presumably excited by the Hall drift current, and likely to be important in the cross-field electron transport. Understanding the relationship between the structure seen in these discharges and the mechanism for operation and ion acceleration is the primary aim of this research.

¥This research is supported by the US Air Force Office of Scientific Research 


\section{Laser-Induced Fluorescence Characterization of Closed-Drift Hall Discharges $\ddagger$}

Prof. Mark A. Cappelli, Principal Investigator, Stanford University William A. Hargus, Graduate Assistant

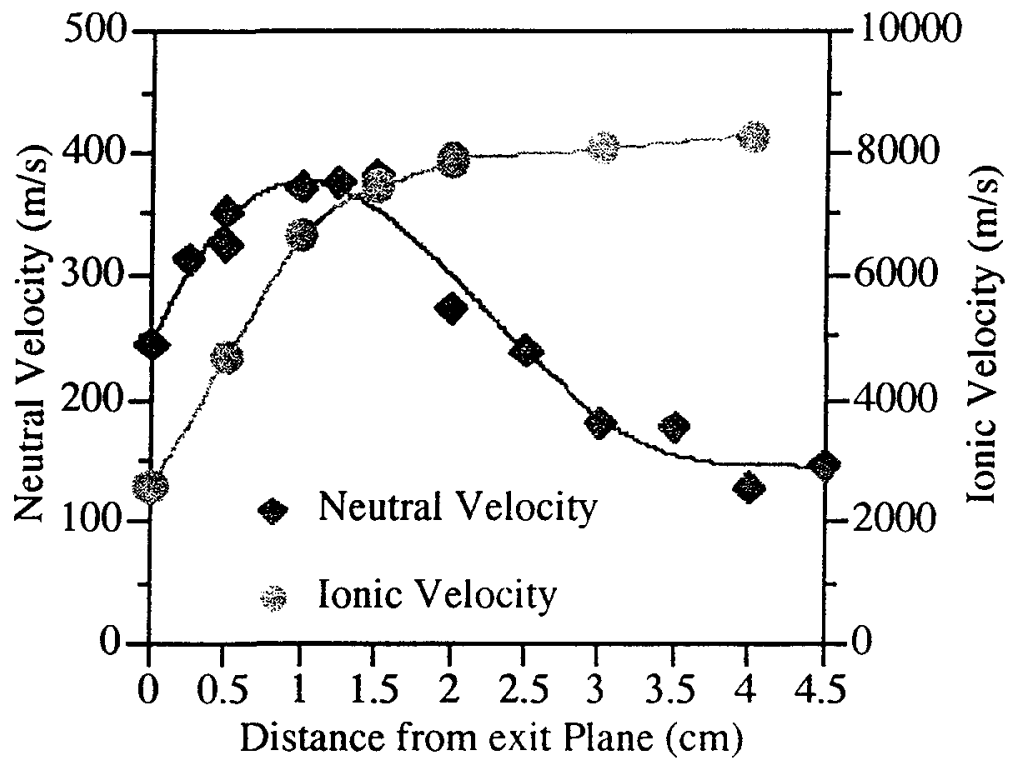

Figure 1. Laser induced fluorescence measurements of neutral and singly-ionized xenon in the plume of a Hall thruster. Neutral xenon velocities increase as a result of charge exchange collisions. The cathode plane is at approximately $\mathrm{x}=2 \mathrm{~cm}$.

The development and application of non-intrusive laser methods of probing Hall discharges offer the opportunity to probe the structure of these devices in regions that are inaccessible with electrostatic probes. Furthermore, they offer the ability to measure properties such as ion and neutral xenon velocities, and temperature that would be difficult to obtain otherwise, in the near-field and channel of the discharge. In recent years, we have been developing laser-induced fluorescence (LIF) methods of interrogating these complex flows. By using a narrowband Nd:YAG-pumped Ti:Sapphire laser and an Art-pumped ring-dye laser tuned to perform selective excitation of an appropriate electronic transition in neutral and ionized xenon, the laser fluorescence collected will reflect the plasma properties in the excitation line shape. When the laser beam is directed into a flowing plasma, the excitation line shape will be broadened and Doppler shifted due to the velocity distribution of the absorbers along the component direction of the incident laser beam. The mean velocity and temperature can be extracted from this distribution.

As an example, the above figure shows the measured velocity variation with axial position for both neutral and singly-ionized xenon. For the neutral xenon measurements, the laser is tuned to excite the $6^{3} \mathrm{P}_{2}-6^{1} \mathrm{D}_{2}$ transition at $823.2 \mathrm{~nm}$. For the ionized xenon measurements, it excites the $5^{4} \mathrm{D}_{7 / 2}-6^{4} \mathrm{P}_{5 / 2}$ electronic transition at $605 \mathrm{~nm}$. We note that in this particular Hall discharge (channel length of $14 \mathrm{~mm}$, cathode plane located at $20 \mathrm{~mm}$ from the exit plane), operating at a voltage and current of $\sim 65-85 \mathrm{~V}$ and $\sim 4.5 \mathrm{~A}$ respectively, we see that the ion acceleration takes place outside of the channel, and that the neutral xenon is also accelerated, presumably through charge exchange collisions with the fast-moving ions. Further evidence of these charge transfer collisions is apparent in the measured velocity distribution functions of the ions. The apparent drop in neutral xenon velocity at a position of $2 \mathrm{~cm}$ is an artifact of the introduction of the slower moving xenon from the cathode. These measurements compliment measurements of time-averaged space potential made using Langmuir probes to provide us with the detailed structure of the time-average plasma in the near-field of these devices.

† This research is supported by the US Air Force Office of Scientific Research 


\title{
HALL THRUSTER AND ION THRUSTER/CATHODE RESEARCH AT THE PLASMADYNAMICS AND ELECTRIC PROPULSION LABORATORY
}

\author{
Alec D. Gallimore \\ University of Michigan
}

\section{Hall Thruster Research at PEPL}

At PEPL hall thruster plume transport properties are characterized with probes, mass spectroscopy, microwave and optical diagnostics. Research on a 5-kW-class SPT is under development with the Air Force Research Lab. The $6 \mathrm{~m}$ by $9 \mathrm{~m}$ PEPL primary test facility is being upgraded by adding four CVI TM-1200 internal cryopumps for a measured xenon pumping speed of over $140,000 \mathrm{l} / \mathrm{s}$, and a base pressure in the low $10^{-7}$ Torr range. PEPL's optical diagnostics capability is enhanced by adding a Laser Induced Fluorescence (LIF) system built around a UV-capable argon ion laser (Coherent Innova Sabre R 20/4) pumping a ring dye laser (Coherent 899-29). A propellant-less Field Emitter Array cathode is under development for hall thrusters. Figures show the $5 \mathrm{~kW}$ SPT designed at PEPL and built at the AFRL. The plume ion energy data is taken $1 \mathrm{~m}$ from a SPT- 100 with a mass spectrometer. The plot shows the existence of multiplycharged xenon ions and suggests that charge-exchange collisions within the thruster plume could account for the high-energy ions detected by energy analyzers.

This research is sponsored by AFOSR.

\section{Ion Thruster Research at PEPL}

We are developing a comprehensive thermal model of the NSTAR ion thruster. A low-power, low propellant-consumption hollow cathode for ion thrusters, hall thrusters, and the Space Station is also being developed. The PEPL cathode test facility has been upgraded by adding a cryopump and a high-fidelity propellant feed system. Developments on laser-based erosion diagnostic systems for ion thrusters are underway.

The top figure shows heat flux from the NSTAR ion thruster operating at $2.3 \mathrm{~kW}$. The space environment was simulated by surrounding the thruster with a box with an emissivity of 1.0 and a temperature of -273 degrees $C$. The bottom figure presents thermography data taken at a wavelength of 10.6 microns. The actual infrared image of these data are taken from the gray-scale picture. The photograph of the cathode is provided for reference.

This research is sponsored by NASA. 


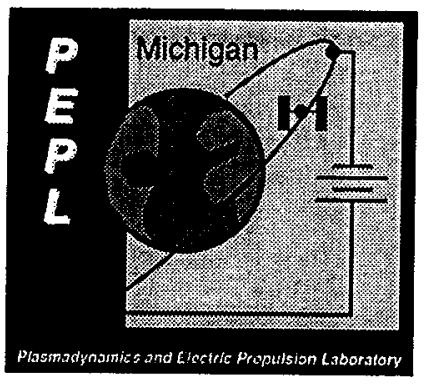

\section{AFOSR-Sponsored Hall Thruster Research at the Plasmadynamics and Electric Propulsion Laboratory}

The University of Michigan, Ann Arbor, MI 48109

Professors: Alec D. Gallimore, Brian E. Gilchrist, \& R. Paul Drake

Students: Lyon B. King, Frank Gulczinski III, James Haas, Colleen Marrese, \& Chris Davis
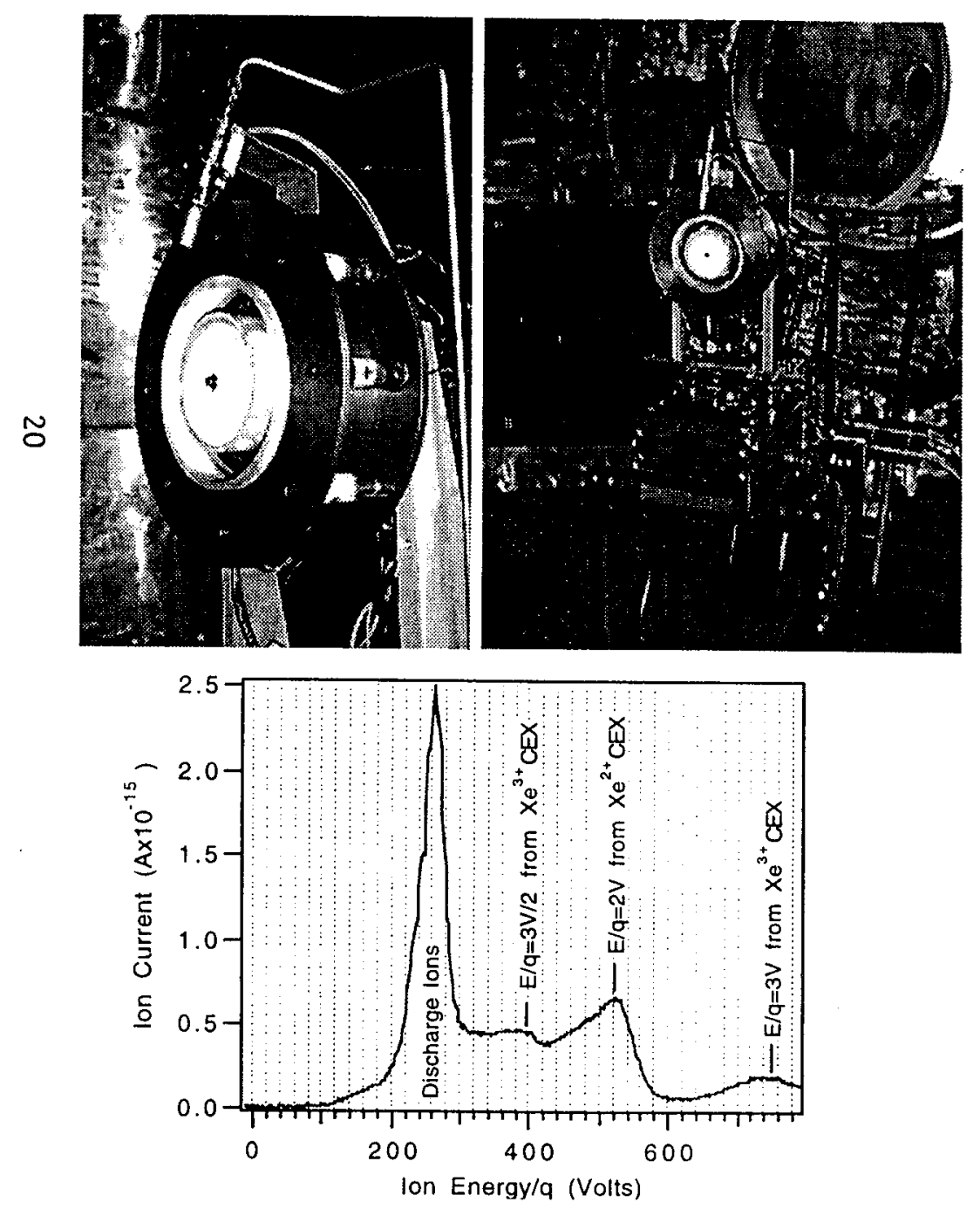

Sponsored Projects:

- Characterizing SPT and TAL plumes with probes, mass spectroscopy, microwave and optical diagnostics

- Develop $5 \mathrm{~kW}$ laboratory-model SPT

- Develop Field Emitter Array Cathode for Hall Thrusters

- Upgrade PEPL primary test facility by adding: $-140,000$ 1/s (on Xe) cryopumping system - state-of-the-art laser diagnostics system

About the Figures: Top - $5 \mathrm{~kW}$ SPT on a NASA-designed thrust stand at PEPL. One of four internal cryopumps is seen in the background. Close-up shows NASALeRC cathode.

Bottom - plume ion energy data taken $1 \mathrm{~m}$ from an SPT-100 with the mass spectrometer. The presence of multiplycharged xenon ions is clearly seen. Charge-exchange collisions may be responsible for high-energy ions detected by energy analyzers. 


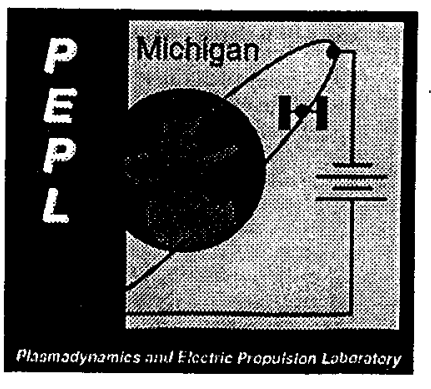

\section{NASA-Sponsored Ion Thruster/Cathode Research at the Plasmadynamics and Electric Propulsion Laboratory}

The University of Michigan, Ann Arbor, MI 48109

\section{Professor Alec D. Gallimore}

Students: Matthew Domonkos, Jon Van Noord, \& George Williams

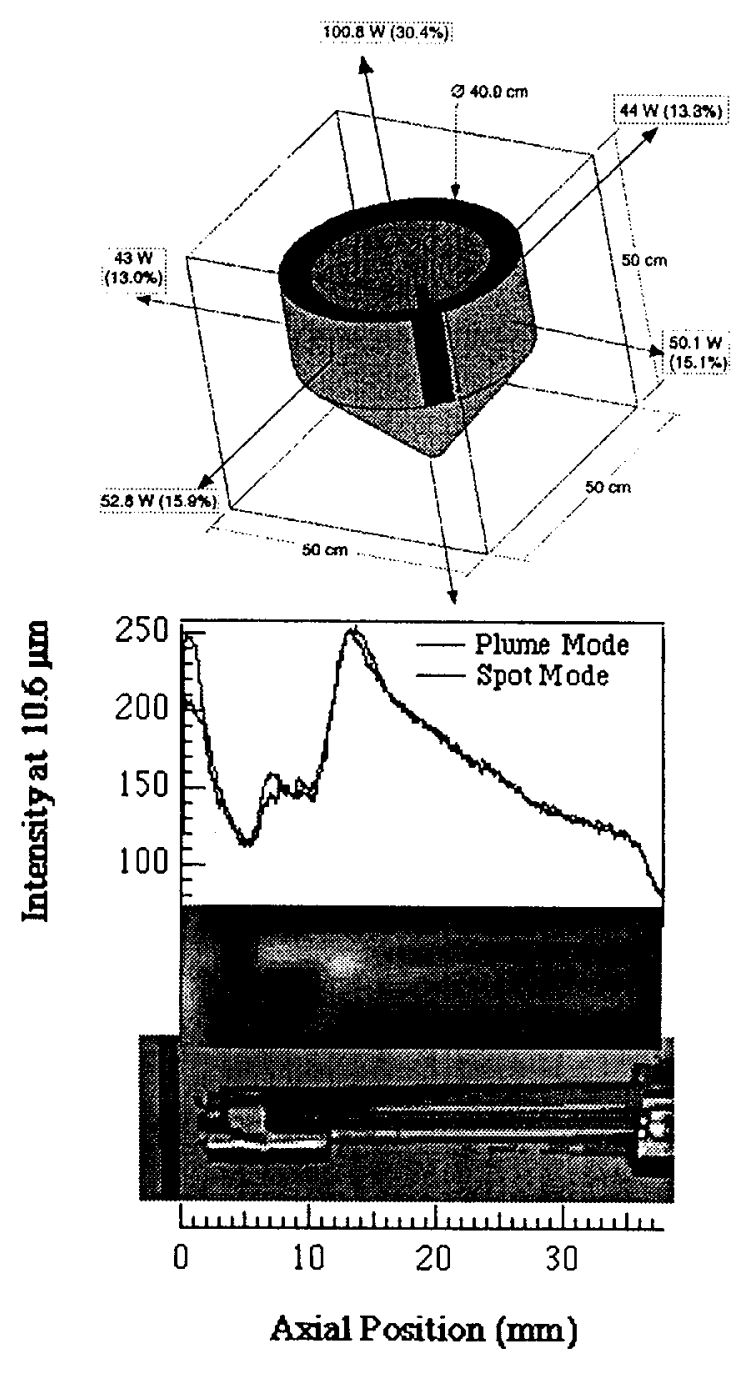

Sponsored Projects:

- Develop comprehensive thermal model of NSTAR ion thruster

- Develop low-power, low-propellant consumption hollow cathode

- Develop laser-based erosion measurement system for ion thrusters

- Upgrade PEPL cathode test facility by adding:

- 7000 1/s (on air) cryopump

- high-fidelity propellant feed system

About the Figures: Top - heat flux from NSTAR ion thruster operating at $2.3 \mathrm{~kW}$. Space was approximated by surrounding the thruster with a box with an emissivity of 1.0 and a temperature of -273 degrees $C$.

Bottom - thermography data at $10.6 \mu \mathrm{m}$. Actual infrared image is shown in gray-scale picture. Photograph of the cathode is provided for reference. 


\title{
PPT RESEARCH
}

\author{
Peter J. Turchi \\ The Ohio State University
}

At The Ohio State University, we use numerical and analytical models and prototype thruster experiments to explore new types and arrangements of propellant ${ }^{1}$, new circuitry ${ }^{2}$, and scaling relations ${ }^{3}$ for both rectangular and coaxial versions of ablation-fed PPTs. We have pioneered the extension and application of the MACH2 code to plasma thruster problems. MACH2 is a 2-1/2 dimensional, unsteady, MHD code ${ }^{4}$ that provides detailed distributions of discharge and flow properties within the PPT. Figure la displays, for example, the computed current distribution in the LES-6 PPT. The Ohio State version ${ }^{5}$ of MACH2 calculates the temperature distribution in the propellant and the associated mass loss and impulse per discharge. Figure $1 \mathrm{~b}$ displays the latter quantities as functions of initial capacitor-energy for the LES- 6 thruster. Propellant evaporation between discharges ${ }^{6}$ adds to the mass loss, as indicated for different assumed values of initial temperature. Figure lc shows the variation with time of temperature profiles within the propellant. Temperatures can exceed values for Teflon decomposition $(\sim 600 \mathrm{~K})$, suggesting the opportunity for mass loss by macroparticles, as noted experimentally?

The complexity of processes in the PPT have encouraged us to pursue experiments in coaxial geometry in order to allow closer comparison with theoretical predictions. Figure 2a displays the computed current distribution for a coaxial PPT. Comparable electromagnetic performance results when rectangular and coaxial PPTs operate at equivalent magnetic field values, as indicated by the MACH2 results in Figure $2 b$. Such performance correlates with a quasi-steady model for PPT behavior at high magnetic Reynolds number ${ }^{3}$. This model also indicates that electromagnetic acceleration of the propellant mass would improve using a current waveform that decreased with time as the propellant surface cooled. An inductive-energy storage circuit ${ }^{2}$ developed at Ohio State provides such a waveform, as demonstrated in experiments with rectangular PPTs (Figure 2c).

NASA Lewis Research Center sponsors our experimental and numerical modeling, while AFOSR/NA supports analytical modeling and the development of a two-temperature, 25 -species model ${ }^{8}$ for Teflon plasma needed by detailed calculations with MACH2. The Ohio Super Computer Center supports these MACH2 computations.

1. Leiweke, R. J., et al, AIAA Paper 95-2916, 1995.

2. Turchi, P. J., et al, AIAA Paper 96-2731, 1996.

3. Turchi, P. J., IEPC Paper 97-038. Proc. of $25^{\text {th }}$ International Electric Propulsion

Conference. Electric Rocket Propulsion Society, 1998. Volume 1.

4. Peterkin, R. E., Jr., et al, "MACH2: A Reference Manual - Fourth Edition", Mission

Research Corporation, Albuquerque, NM, 1989.

5. Turchi, P. J. and Mikellides, P. G., AIAA 95-2915, 1995.

6. Mikellides, P. G. and Turchi, P. J., AIAA 96-2733, 1996.

7. Spanjers, G. G., et al, AIAA Paper 96-2723, 1996.

8. Schmahl, C. S. and Turchi, P. J., IEPC Paper 97-124, Proc. of $25^{\text {th }}$ International

Electric Propulsion Conference. Electric Rocket Propulsion Society, 1998. Volume 2. 


\section{COMPUTATIONAL MODELING AT OHIO STATE PROVIDES INSIGHTS FOR IMPROVED PPT PERFORMANCE.}

\section{COMPARISON OF MACH2 CALCULATIONS} WITH LES-6 EXPERIMENTAL DATA

\section{DISTRIBUTION OF LES-6 PPT $(t=0.4 \mu \mathrm{SEC})$}

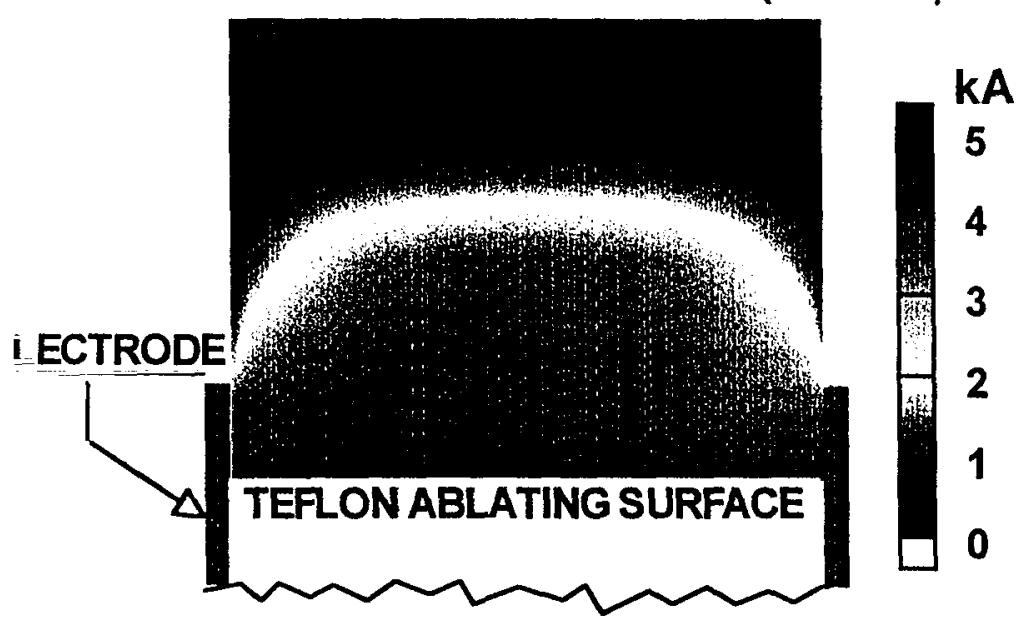

PROPELLANT TEM PERATURE PROFILES IDICATE VALUES ABOVE TEFLON DECOMPOSITION

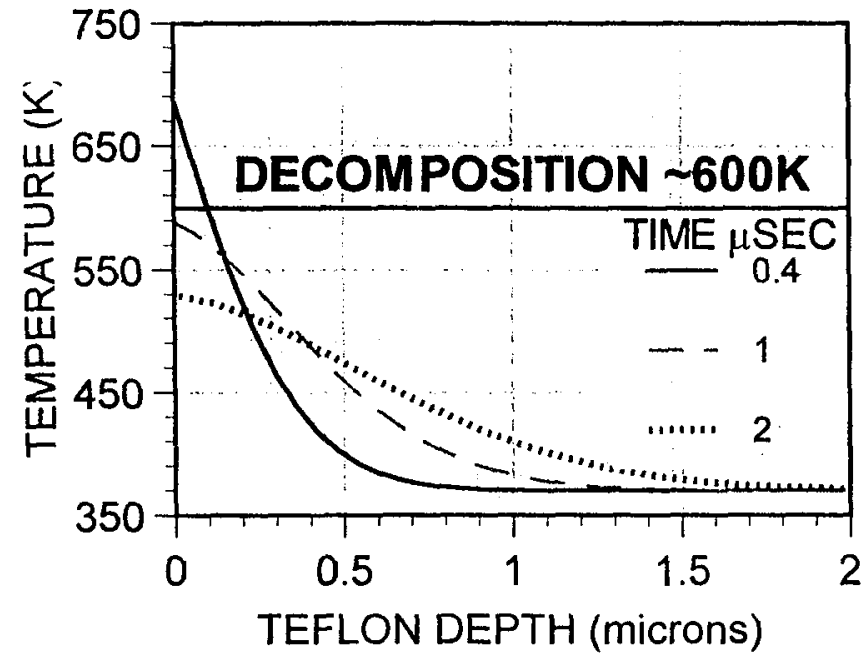

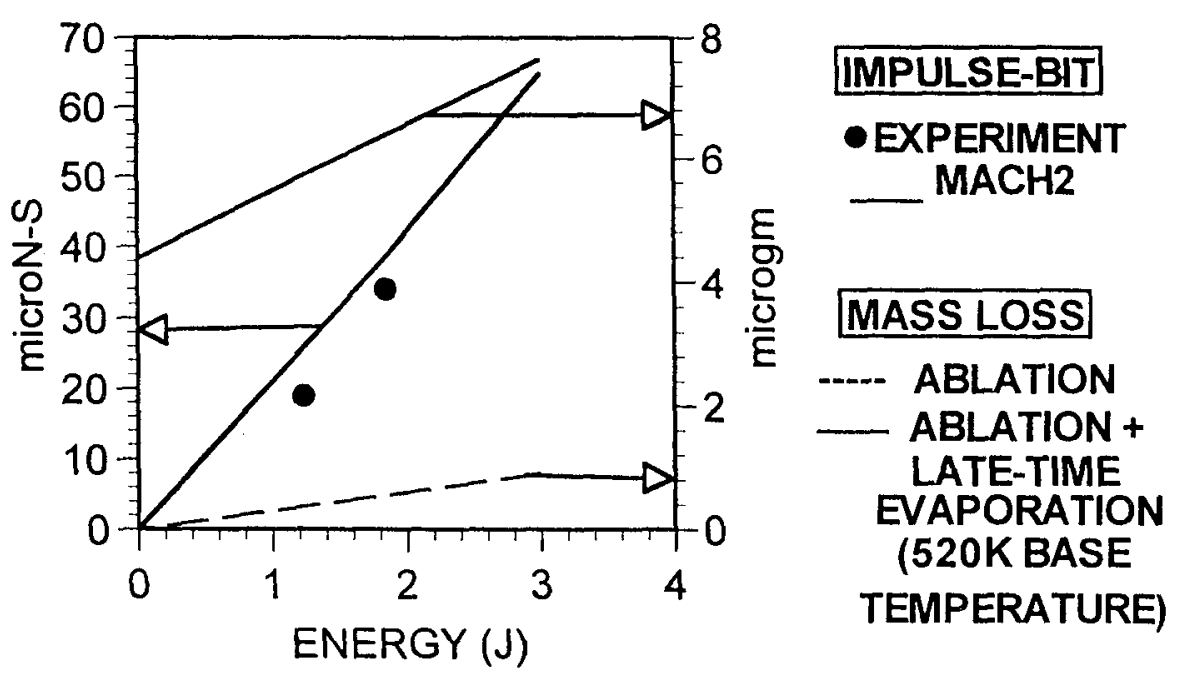

MACH2 CODE AT OSU PROVIDES DETAILED INSIGHTS INTO PPT BEHAVIOR INCLUDING CURRENT AND TEMPERATURE DISTRIBUTIONS.

THESE INSIGHTS ASSIST IN UNDERSTANDING PROPELLANT LOSS MECHANISMS LEADING TO IMPROVED DESIGN FOR THE NEXT GENERATION OF PPTS. 


\section{NUMERICAL AND ANALYTICAL MODELING HAS LED OHIO STATE TO PURSUE NEW GEOMETRIES AND CIRCUITS FOR IMPROVED PPT PERFORMANCE.}

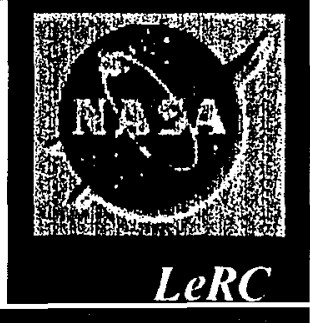

MACH2 CALCULATION OF CURRENT DISTRIBUTION OF COAXIAL PPT $(t=0.5 \mu$ SEC $)$

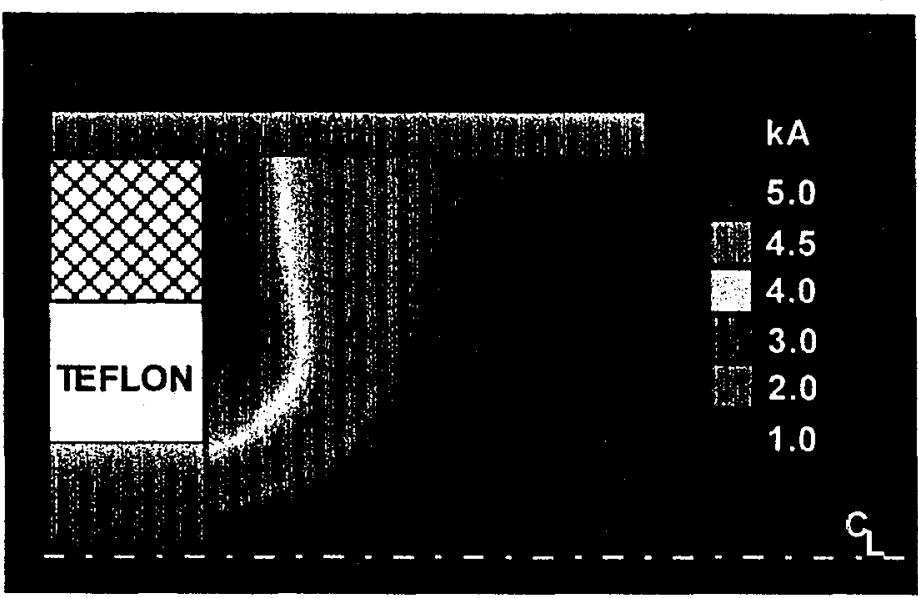

$\approx$ EXPERIMENTAL CURRENT WAVEFORM FOR INDUCTIVELY-DRIVEN PPT

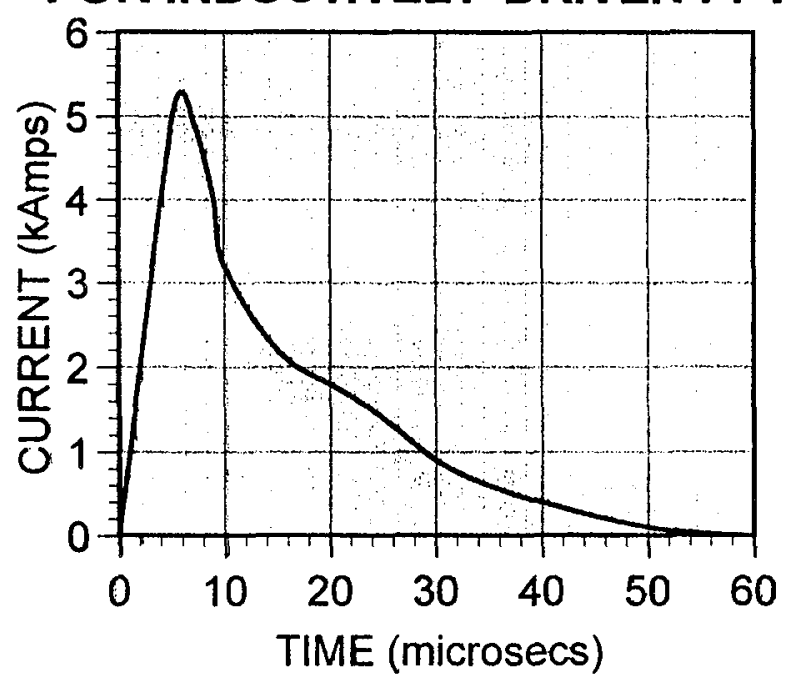

PPT PERFORMANCE COMPARISONS

- COAXIAL $\approx$ RECTANGULAR

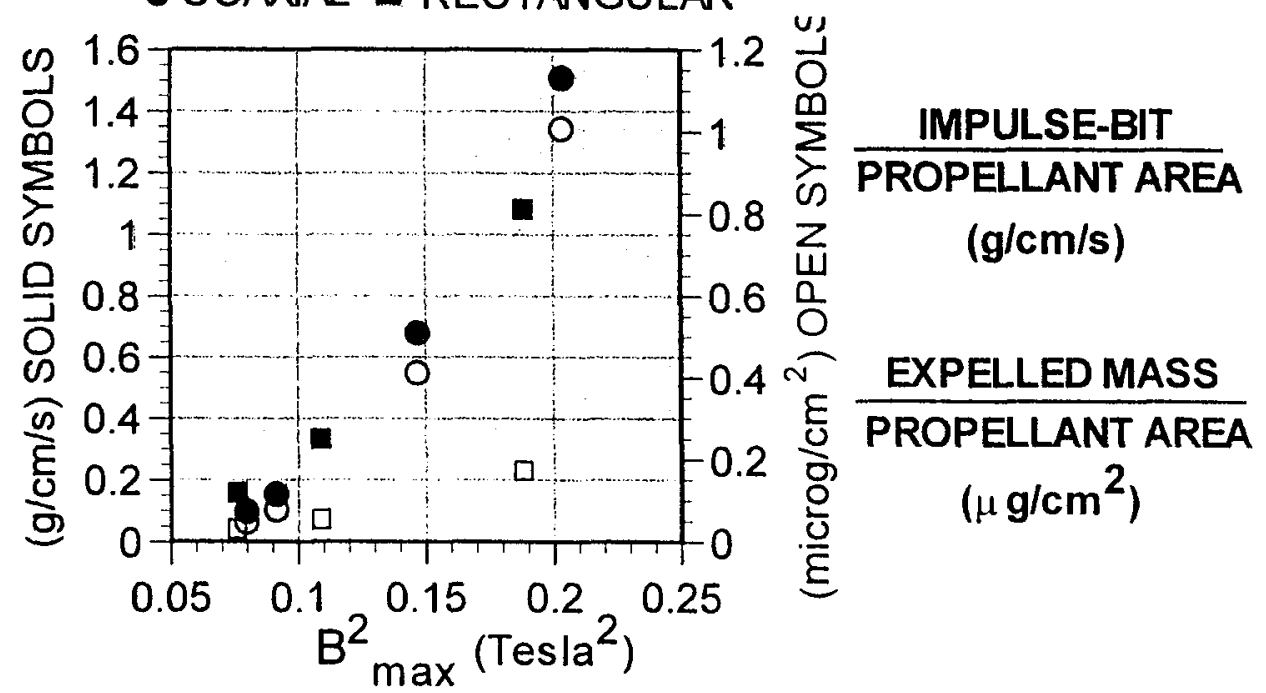

COAXIAL THRUSTERS PERMIT CLOSER COMPARISON OF EXPERIMENT AND THEORY LEADING TO BETTER UNDERSTANDING OF PPT PERFORMANCE.

OINDUCTIVE ENERGY STORAGE CIRCUITS IMPROVE PPT PERFORMANCE BY CONTINUING ELECTROMAGNETIC ACCELERATION AS THE SURFACE COOLS. 


\title{
ELECTRIC PROPULSION RESEARCH AT COLORADO STATE UNIVERSITY
}

\author{
Paul J. Wilbur \\ Colorado State University
}

Electric propulsion research concentrates on fundamental problems related to ion thrusters

Atoms of nitrogen or carbon are ion implanted into molybdenum and titanium ion thruster grid materials. The resulting samples are sputter-eroded in a xenon ion beam to measure erosion rates. Preliminary results show that erosion rates of Mo - sputtered grid materials are $1 / 2$ to $1 / 3$ of those for unimplanted grid materials.

The research examines the effects of ion optics parameters such as grid dish depth and beam current on charge exchange production of ions in an ion thruster beam plasma. Numerical modeling yields the lowenergy ion current density distribution at the boundary of the beam. This information can be used to compute fluxes of contaminating ions on spacecraft surfaces.

This research was conducted by I. Kameyama and is reported in AIAA Paper No. 98-3794. It is sponsored by NASA Lewis Research Center.

A study of alternate propellants for ion thrusters suggests that the $C_{60}$ molecule is probably not a suitable ion thruster propellant for low specific impulse missions, as early studies suggested it might be. It has been found that $\mathrm{C}_{60}$ not only fragments in a plasma discharge but forms negative ions. Both effects yield poor performance as demonstrated in this experimental work that employed both DC and radio frequency discharge chambers.

This research was conducted by J. S. Snyder and is sponsored by the Jet Propulsion Laboratory.

This experimental study has developed a hollow cathode that can be operated at near-ambient cathode temperatures. Teflon is the expellant currently being used. Using a solid propellant enables operation without a gas handling and storage system.

This research is conducted by D. Burtner. 


\title{
ELECTRIC SPACE PROPULSION RESEARCH AT THE SPACE POWER INSTITUTE
}

\author{
Ivana Hrbud \\ Auburn University
}

The Space Power Institute is involved in a wide range of power and propulsion activities including: energy storage device development (fuel cells, supercapacitors, TP power generation); space diagnostics and hypervelocity impact; advanced propulsion techniques; power conditioning, control, and management; microelectronics; thermal management modeling; advanced material technology, and metal casting. For the past five years, electric space propulsion research has been conducted at the Institute which was motivated by the New Millennium Program initiated by NASA in 1994. During this period, we have achieved significant accomplishments in a multitude of areas such as innovative power and storage systems (capacitor technology), power train/network simplification, thruster and mission performance, etc. In particular, we have successfully demonstrated the operation of a Hall-ion thruster (TAL/D-55) in a long-pulse, direct-drive mode. The TAL was directly powered by energy stored in a chemical double layer (CDL) capacitor bank which would be charged from the solar panel bus with minimal network circuitry. This allowed thrust generation for 3-6 minutes and subsequent parametric analysis revealed competitive performance characteristics. A mission analysis on the ORACLE spacecraft was performed to further evaluate the concept and compare with other propulsion schemes. The results showed a major advantage when compared with the other electric propulsion approaches considered in this analysis. The power needed to be generated on the spacecraft for electric propulsion is extremely reduced in direct-drive operation. This has major consequences on cost, complexity, mass/volume/area (solar panels), drag, mission profile, etc. of the spacecraft. The resuits of other target characteristics considered in the mission analysis showed competitive performance of all propulsion options taken into account. Other research projects involve alternative capacitor technology for energy storage and power system options in pulsed plasma thruster (PPT). Multi-layer ceramic (MLC) capacitors promise to be viable candidates which used in a Marx bank concept could give rise to many benefits/advantages (such as low power demand on spacecraft, low charge voltages, packaging, minimizing unintentional high voltage breakdown, etc.). We investigated the mass $\mathrm{x}$ (times) volume factor of MLC capacitors and present capacitor technology used in PPT operation. This alternative capacitor technology has the potential to lower this factor by 1 to 2 orders of magnitude. In preliminary tests, we operated a MLC unit with discharge currents exceeding $10 \mathrm{kA}$ at a charge voltage of $350 \mathrm{~V}$.

Due to the background of the Institute, our main objectives are to explore a wide range of power system options which will reduce cost, mass/volume, complexity and increase application range, lifetime, reliability of electric propulsion systems. Our present and future foci are pulsed plasma thruster, power(-on-a-chip) and thrusteron-a-chip, and their individual power systems. 
* OBJECIIVE is to explore a wide range of power system options which will reduce cost, mass/volume, complexity, and increase application range, lifetime, reliability of electric propulsion systems.

* Approach:

L Long-Pulse, Direct-Drive EP \& Supercapacitors (CDL)

ᄉ Power System Architecture

- Marx Bank Concept

- Ceramic Capacitors

ᄉ Electric Propulsion Systems

- Hall-Ion Thrusters

- Pulsed Plasma Thrusters

* Sponsoring Agencies:

A NASA Lewis Research Center

A NASA CCDS / SPI
* Goals 1998/99:

- Evaluate alternative capacitor technologies (life, durability, etc.).

+ Identify improvements in advanced capacitor technology.

$\downarrow$ Investigate high voltage breakdown and space environment effects of innovative power systems.

+ Reduce volume and mass of present power systems. 


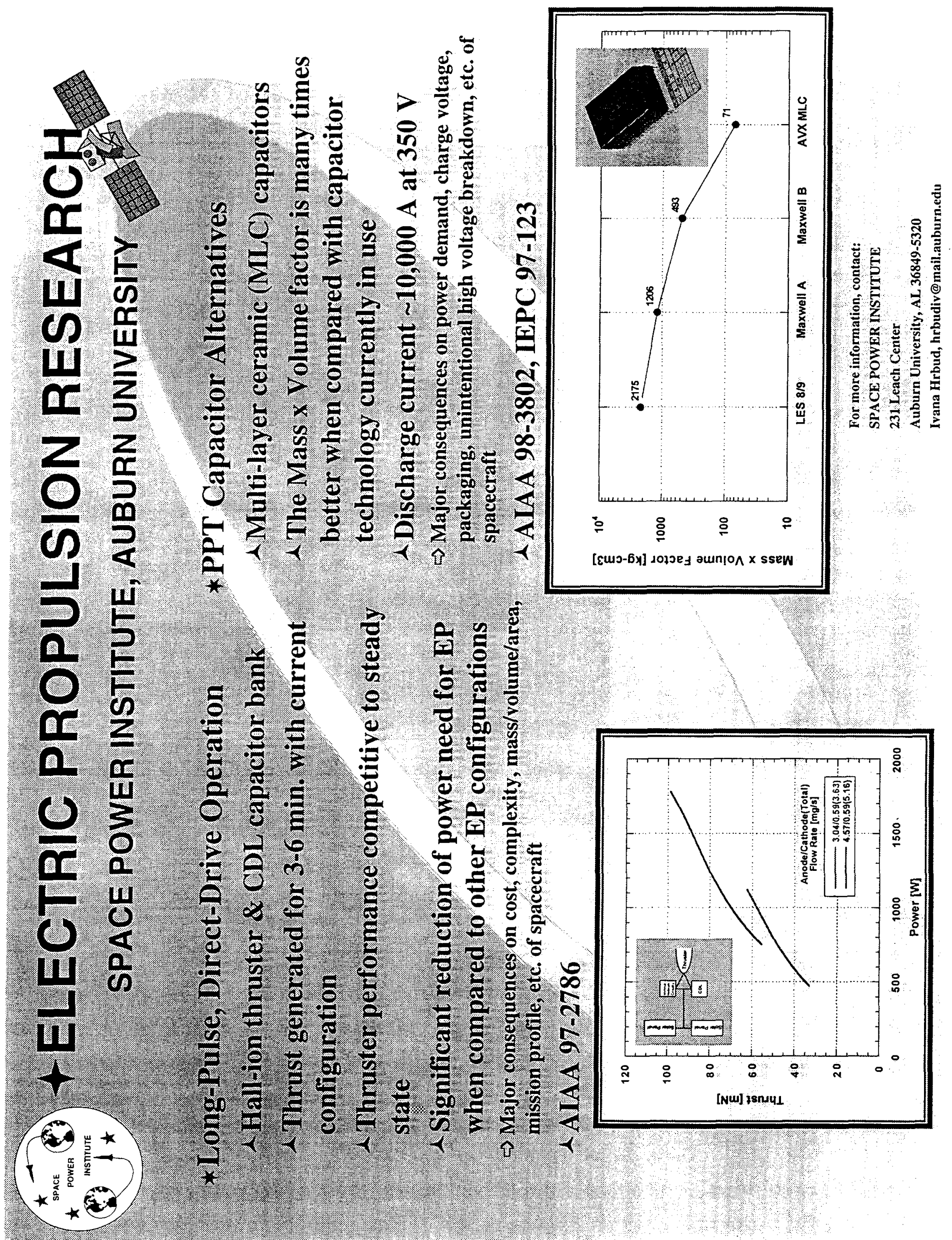




\title{
PLASMA PROPULSION RESEARCH AT PRINCETON UNIVERSITY'S EPPDYL
}

\author{
Edgar A. Choueiri \\ Princeton University
}

Low Power: The Gas-Fed Pulsed Plasma Thruster. Five generations of gas-fed pulsed plasma thrusters (GF-PPTs) have been designed, built and studied at EPPDyL over the past two years in collaboration with Science Research Labs. The GF-PPT offers performance and operational advantages over the ablative PPT at the price of higher complexity. The low mass utilization efficiency problem that plagued previous gas-fed pulsed thrusters was solved using a scheme based on high repetition rate pulsing of the discharge. This past year the focus of the experimental work has been on: 1) raising the thrust-to-power ratio at fixed efficiency, 2) studying the effects of discharge initiation and symmetry on the performance and 3) quantifying the effects of testing environment contamination on performance measurements at low mass bits (below $1 \mu \mathrm{g} / \mathrm{shot}$ ). On the theoretical front, a detailed parametric description of the scaling of GF-PPT performance was found as a function of five non-dimensional scaling parameters derived by applying dimensional analysis on a model that is based on an inductor-capacitorresistor (LCR) series circuit analog for energy addition, and a "snow-plow" model for mass accumulation and momentum conservation. The model includes a spatially exponential initial mass distribution and a contoured outer electrode. A numerical solution can be found when the following five non-dimensional scaling parameters are specified: the resistance parameter, $\psi$, is a ratio of the circuit resistance to the critically damped circuit resistance. The dynamic impedance parameter, $\alpha$, is a measure of how quickly the inductance is changing in the circuit. The initial mass parameter, $\rho_{0}$, is related to the fraction of mass taken up initially by the current sheet. The mass distribution parameter, $\gamma$, is the spatial exponential constant in the overall mass distribution. The electrode geometry parameter, $\lambda$, is a measure of the slope of the outer electrode. After many calculations spanning over the nondimensional parameter space, parameter values that maximized performance were found. The figure above, for instance, shows how small values of the resistance parameter lead to high values for the efficiency and thrust-topower ratio. Also, when the resistance parameter is small, an optimum value of the dynamic impedance parameter exists near $\alpha=1$. In general, large values of the dynamic impedance parameter lead to high efficiencies, however the electrode length to achieve these values can be too large. The parametric study led to many other prescriptions for improving the performance of PPTs.

High Power: The Lithium Lorentz Force Accelerator.

The Li-LFA is the new generation steady-state magnetoplasmadynamic thruster (MPDT) that uses a multi-channel cathode and lithium propellant to provide high efficiency and long lifetime previously unattainable with gas-fed MPDTs. Under JPL sponsorship, a 30-100 kW level thruster has been developed in collaboration with Thermacore Inc. The thruster has a novel lithium mass flow rate system that relies on advanced heat pipe technology and calorimetry to allow control of the mass flow rate of lithium vapor (at and above $1000 \mathrm{C}$ ) without any mechanical or moving parts. Recent work focused on 1) detailed thermal modeling of the device, 2) improvement of the cathode heating scheme and 3) development of specialized diagnostics including multi-color pyrometry, CCD-based emission spectroscopy and a new water-cooled thrust stand for performance characterization in the $100 \mathrm{~kW}$ range.

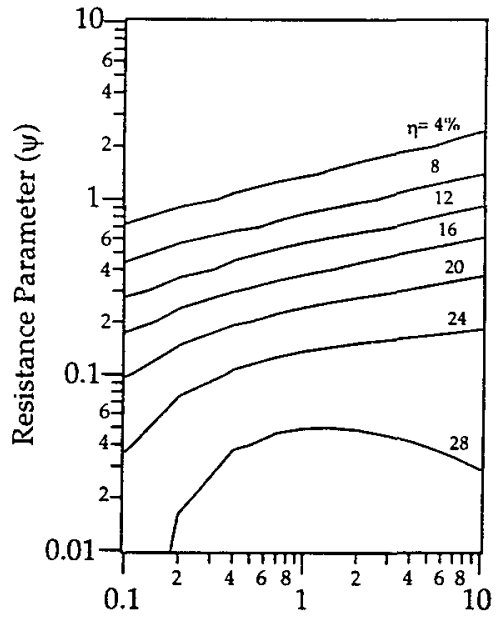

Dynamic Impedance Parameter $(\alpha)$

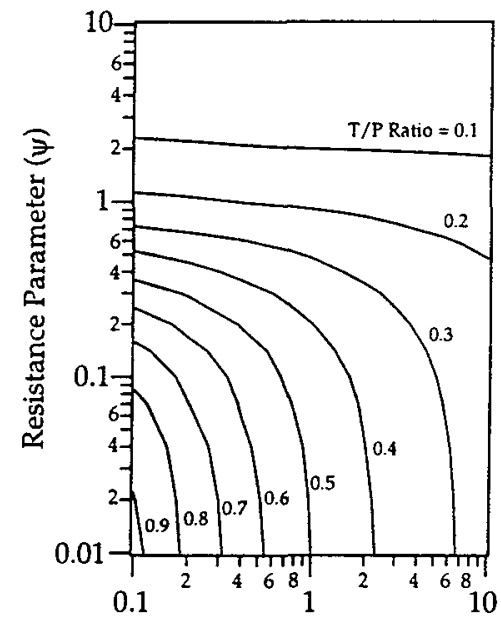

Dynamic Impedance Parameter $(\alpha)$

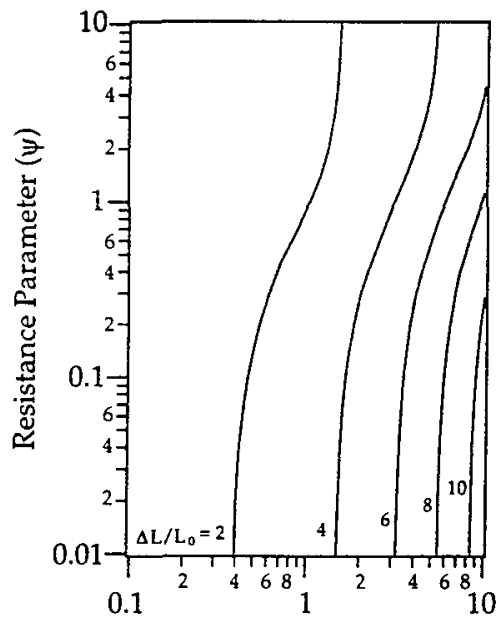

Dynamic Impedance Parameter $(\alpha)$

Figure 1: Efficiency, thrust to power ratio and optimum electrode length calculations for a co-axial gas-fed pulsed plasma thruster with a uniform mass distribution. 


\begin{tabular}{ll|l|l|}
\hline & High Power Plasma Propulsion Work at \\
Princeton
\end{tabular}




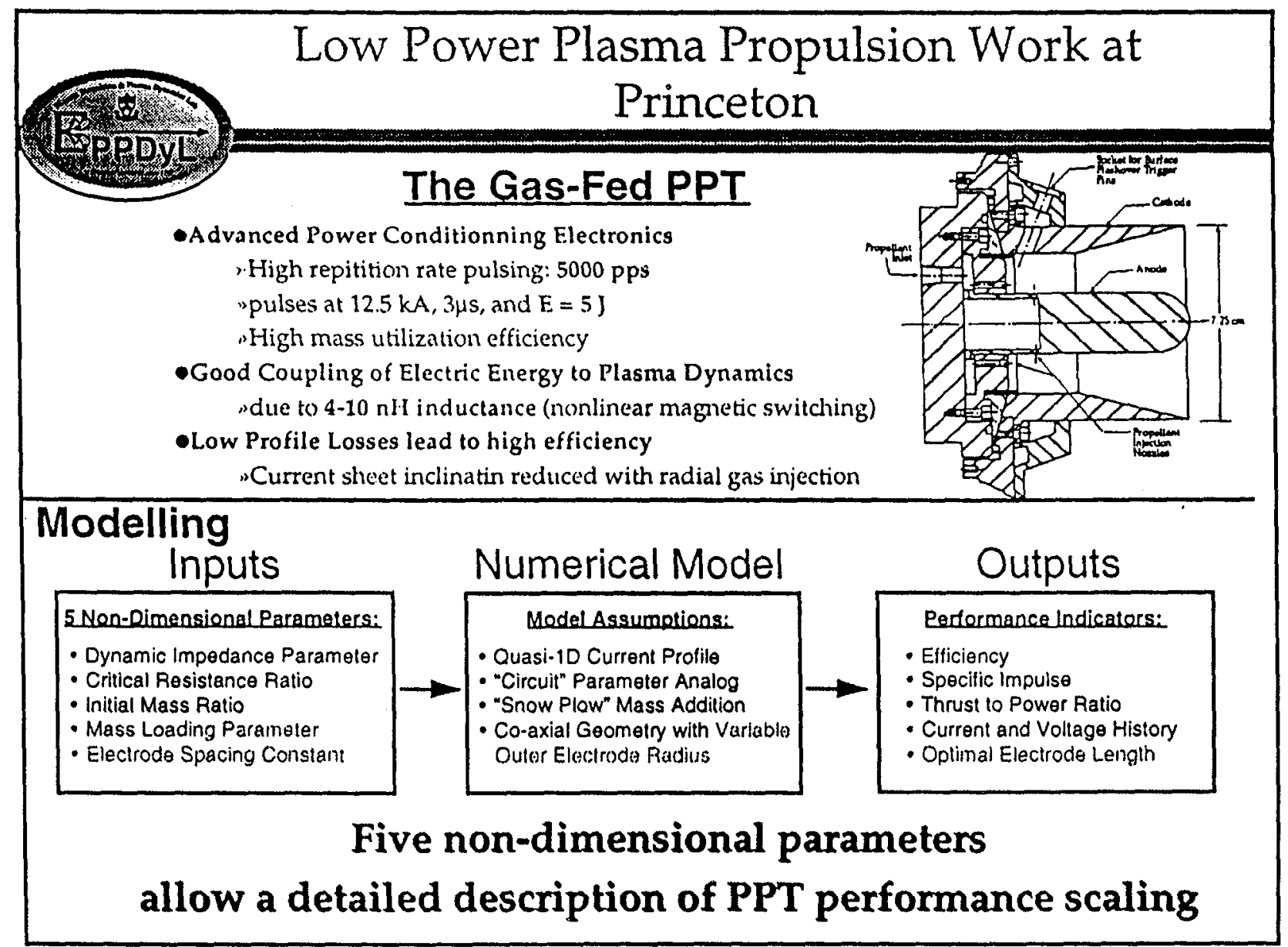




\title{
ELECTRIC PROPULSION RESEARCH AT ILLINOIS
}

\author{
Rodney L. Burton \\ Department of Aeronautical and Astronautical Engineering \\ University of Illinois at Urbana-Champaign
}

DC Arcjet. Previous work, in collaboration with $\mathrm{H}$. Krier, has concentrated on detailed experimental and numerical analysis of the $1 \mathrm{~kW}$ hydrazine arcjet. Electrostatic probes swept across the exit plane measured electron density, electron temperature and ion Mach number. ${ }^{1}$ Time-of-flight probes measured ion velocity, and indirectly, ion temperature. ${ }^{2}$ Electrostatic probes mounted flush in the nozzle wall measured floating potential, sheath potentials, electron density and temperature, and current density. 3,4 A temperature and chemical non-equilibrium code was developed and was validated using the code results. ${ }^{5-7}$ The picture of the arcjet was completed with models for the cathode sheath potential. ${ }^{8}$

Pulsed Arcjet. The pulsed arcjet is a high repetition rate $(1000-3000 \mathrm{~Hz})$ low-power $(25-500 \mathrm{~W})$ device operating on a variety of gaseous propellants in the $200-400$ second range. Its principle advantage is the ability to operate at power levels as low as $25 \mathrm{~W}$ with non-toxic propellants. An extensive thrust stand and analytical study ${ }^{9}$ was performed with helium propellant in which thrust efficiencies were achieved as high as $57 \%$ at $32 \mathrm{~W}$. Modeling of an individual pulse was also performed.

Pulsed Plasma Thruster. The PPT is being developed in a coaxial geometry, using an advanced external pulse circuit. A ceramic nozzle is used to extract gasdynamic thrust, and a large annular cathode is used to increase electromagnetic thrust. A compact thrust stand has been developed and used to measure high values of specific thrust at $600 \mathrm{~s}$ specific impulse. ${ }^{10}$ Detailed electrostatic and magnetic probe measurements of the thruster plasma are combined with performance measurements to understand the acceleration process and optimize performance. ${ }^{11,12}$ Laser interferometry is being employed to measure neutral and electron density in the plume in a collaborative effort with AFRL, Edwards AFB.

Students. The research is being conducted by graduate students S. Bushman, E. Antonsen, F. Rysanek, J. Konicek and $\mathrm{S}$. Keener, and by undergraduates T. Smart and J. Norris.

Support. This research has been supported by AFOSR, NRL, NASA Lewis, and AFRL (Edwards).

\section{$\underline{\text { References }}$}

1. Burton, R. L. and Bufton, S. A., "Exit-Plane Electrostatic Probe Measurements of a Low-Power Arcjet,"

J. of Propulsion and Power, 12, 6, 1099-1106, Nov.-Dec., 1996.

2. Bufton, S. A., and Burton, R. L., "Velocity and Temperature Measurements in a Low-Power Hydrazine

Arcjet," J. of Propulsion and Power, 13, 6, 768-774, Nov.-Dec., 1997.

3. Tiliakos, N. T. and Burton, R. L., "Arcjet Anode Sheath Voltage Measurements by Langmuir Probe," J. of

Propulsion and Power, 12, 6, 1174-1176, Nov.-Dec., 1996.

4. Tiliakos, N. T., Burton, R. L., and Krier, H. "Arcjet Anode Plasma Measurements Using Electrostatic Probes," $J$. of Propulsion and Power, 14, 4, 560 - 567, July-Aug., 1998.

5. Megli, T. W., Krier, H., Burton, R. L., and Mertogul, A. E., "Two-Temperature Plasma Modeling of

Nitrogen/Hydrogen Arcjets," J. of Propulsion and Power, 12, 6, 1062-1069, Nov.-Dec., 1996.

6. Megli, T. W., Krier, H., and Burton, R. L., "Plasmadynamics Model for Nonequilibrium Processes in

$\mathrm{N}_{2} / \mathrm{H}_{2}$ Arcjets," J. of Thermophysics and Heat Transfer, 10, 4, 554-562, Oct.-Dec. 1996.

7. Megli, T. W., Lu, J., Krier, H., and Burton, R. L., "Modeling Plasma Processes in $1 \mathrm{~kW}$ Hydrazine Arcjet Thrusters," J. of Propulsion and Power, 14, 1, 29-38, Jan.-Feb., 1998.

8. Lu, J., Krier, H., Burton, R. L., Goodfellow, K. D., "Collisionless Cathode Sheath Models for $1 \mathrm{~kW}$ Hydrazine

Arcjets," J. of Thermophysics and Heat Transfer, 12, 2, 230-238, Mar-Apr., 1998.

9. Willmes, G. F., "A Low Power Pulsed Arcjet Thruster for Spacecraft Propulsion," Ph.D. Thesis, University of Illinois at Urbana-Champaign, 1997.

10. Wilson, M. J., Bushman, S. S., and Burton, R. L., "A Compact Thrust Stand for Pulsed Plasma Thrusters," IEPC Paper No. 97-122, 25th Int. Elec. Prop. Conf., Cleveland, Aug., 1997.

11. Burton, R. L., Wilson, M. J., and Bushman, S. S., "TITLE," AIAA Paper No. 98-3660, 34th Joint Propulsion Conference, Cleveland, July, 1998.

12. Bushman, S. S, Burton, R. L., and Antonsen, E. A., "Arc Measurements and Performance Characteristics of a Coaxial Pulsed Plasma Thruster," AIAA Paper No. 98-3660, 34th Joint Prop. Conf., July, 1998. 
University of Illinois/Urbana-Champaign

\section{Coaxial Pulsed Plasma Thrusters}

- Coaxial PPT

-- side feed, nozzle

- Compact Thrust Stand

-- $50 \mu \mathrm{N}, 24$ " footprint
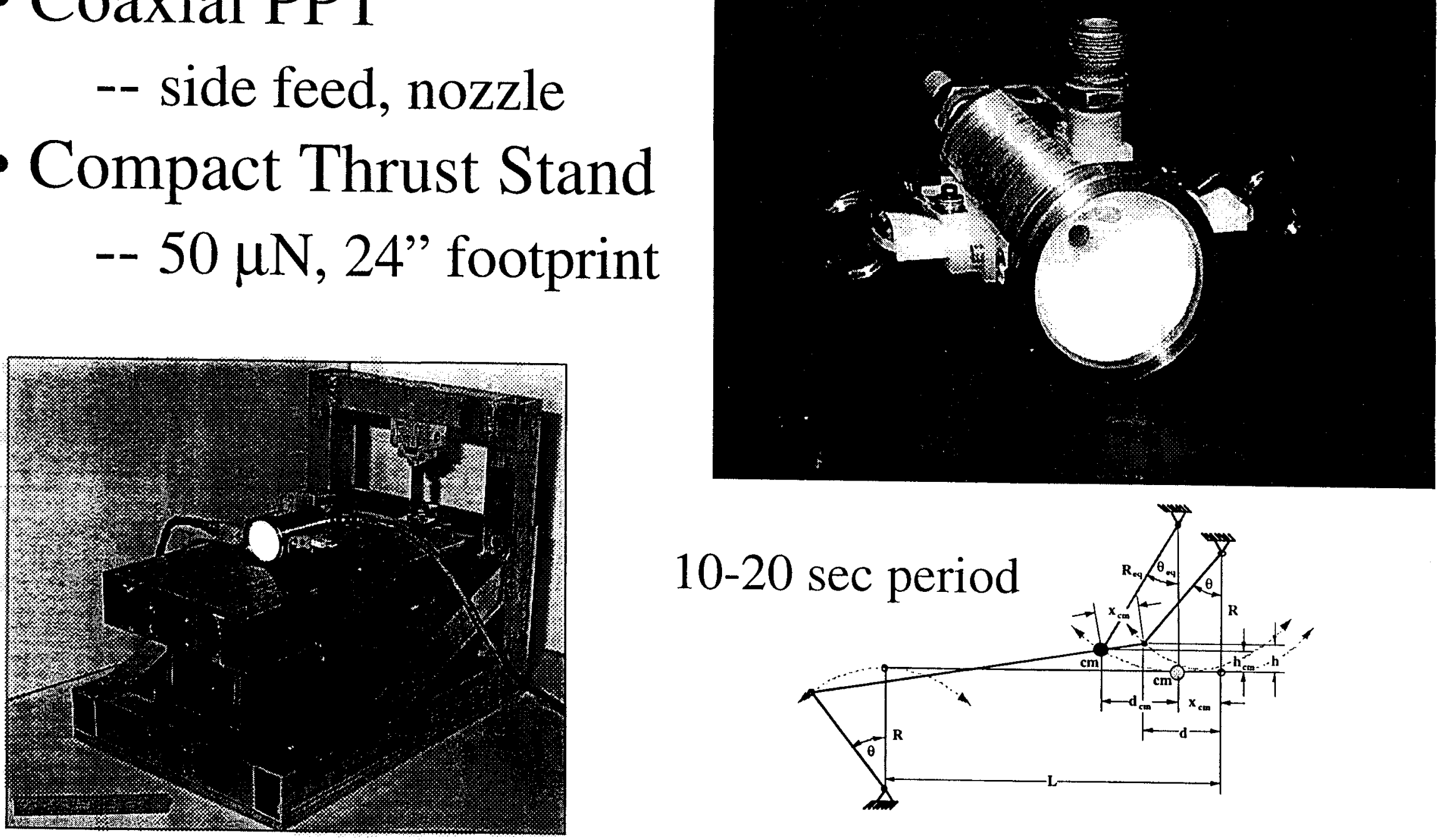
University of Illinois/Urbana-Champaign

\section{Coaxial Pulsed Plasma Thrusters}

- Magnetic Probes

- Quadruple Electrostatic

- Laser Interferometry (AFRL)・ Neutral Density

- Thrust and Mass Loss

- Heating Measurements

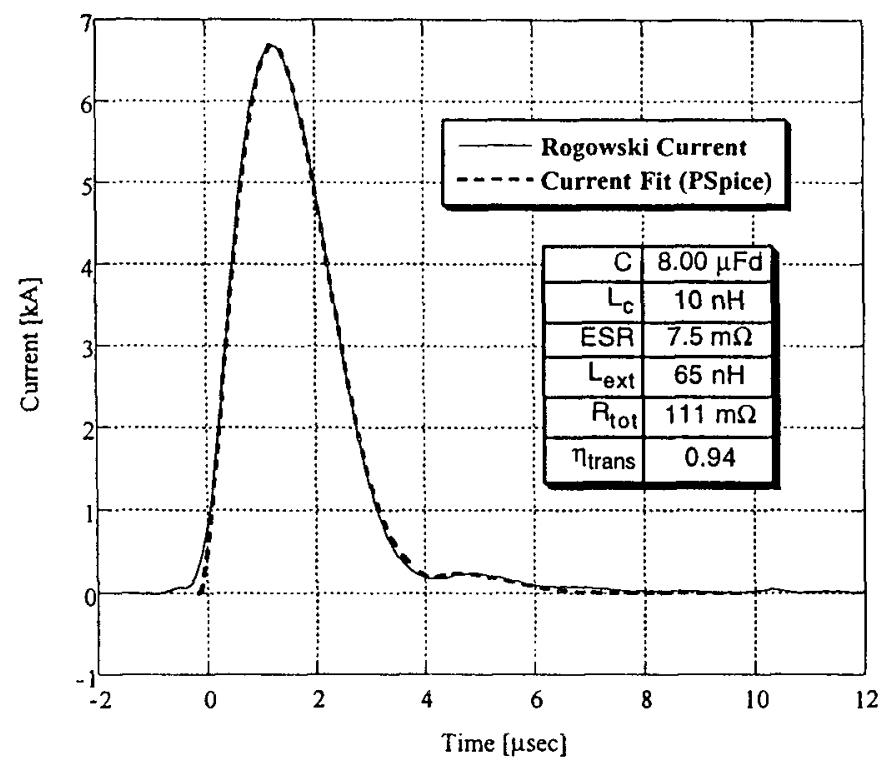

- Current Profiles

- Electron Temp. and Dens.

- Isp and Efficiency

- Heat loss Efficiency

Results:

- 40 - $60 \mu \mathrm{N}$-s per joule

- $\mathrm{I}_{\mathrm{sp}}>500 \mathrm{~s}$

- Efficiency to $18 \%$

- Code Validation (MACH2)

Funding: AFOSR, NASA Lewis, AFRL 